\title{
A systematic review of the impact of adjusting input dynamic range (IDR), electrical threshold $(T)$ level and rate of stimulation on speech perception ability in Cochlear Implant users.
}

Nunn $\mathrm{T}^{1,2}$, Jiang $\mathrm{D}^{2}$, Green $\mathrm{T}^{3}$, Boyle $\mathrm{P}^{4}$, Vickers $\mathrm{D}^{3}$

${ }^{1}$ University College London, Ear Institute, 332, Gray's Inn Road, London. WC1X 8EE,

${ }^{2}$ Guy's and St Thomas' NHS Trust, Hearing Implant Centre, Westminster Bridge Road,

London. SE1 7EH, ${ }^{3}$ University College London, Speech, Hearing and Phonetic Sciences, 2 ,

Wakefield Street. London. WCIN 1PF, ${ }^{4}$ Advanced Bionics GmbH, European Research

Centre, Feodor-Lynen Str. 35, 30625 Hannover, Germany

Corresponding Author

Mr Terry Nunn

Guy's and St Thomas' NHS Trust, Hearing Implant Centre, Westminster Bridge Road, London. SE1 7EH

Tel: +44 2071886245

Fax: +44 2071888905

E-mail: terry.nunn.15@ucl.ac.uk

Acronyms:

CI - Cochlear Implant

ASC - Automatic Sensitivity Control

AGC - Automatic Gain Control

EDR - Electrical Dynamic Range

IDR - Input Dynamic Range

IIDR - Instantaneous Input Dynamic Range 


\title{
A systematic review of the impact of adjusting input dynamic range (IDR), electrical threshold $(T)$ level and rate of stimulation on speech perception ability in Cochlear Implant users.
}

\begin{abstract}
:
Objective: To systematically review the evidence of how adjustments of the electrical T Level, Input Dynamic Range (IDR) and electrical stimulation rate impact on speech perception for cochlear implant (CI) users. Design: Systematic review. Study sample: A search of two electronic data sources yielded 32 studies, which met the inclusion criteria. A quality assessment and two evidence-based practice (EBP) review rating schemes were used to grade studies. Results: Due to the heterogeneity of speech perception measures, CI device type and study design, comparisons were made by structured review. Conclusion: The quality of studies was found to be moderate to poor. Increasing $\mathrm{T}$ levels above behavioural threshold, or as proportion of electrical dynamic range (EDR), has been demonstrated to improve perception of monosyllables in quiet and sentences in both quiet and in noise. Specific IIDR and IDR setting may improve perception of monosyllables in quiet and sentences in noise. However, no recommendation could be determined for setting rate of stimulation as speech perception varied significantly across rates examined. To optimise speech perception, a bespoke approach to parameter setting providing a individualised CI fitting is recommended; however, detail of how to optimise settings and the interactions between parameters is as yet unknown.
\end{abstract}

Keywords: Cochlear implants; Speech perception; Stimulation rate; Input Dynamic Range 


\section{Introduction:}

Continuing development in signal processing techniques, changes in implant candidacy criteria and improved preservation of residual hearing have all contributed to better speech perception abilities in cochlear implant (CI) users (Balkany et al. 2007; Di Lella et al. 2010; Blamey et al. 2012). However, despite these reported improvements, a limitation remains for CI users when detecting speech presented at soft intensity levels or in the presence of noise (Donaldson et al. 2009; Boyle et al. 2013).

There are several programmable parameters which define how a CI delivers stimulation to the auditory system. Although not an exhaustive list, programmable parameters include the minimum and maximum electrical stimulation levels, the number of active stimulating electrodes, the range of acoustic information captured prior to electrical transduction and the overall rate of electrical stimulation. Setting these parameters is performed with the intention to ensure the electrical stimulation pattern generated by the CI provides optimal hearing benefit and speech perception. While the effect on speech perception of several changes to parameters have been evaluated (Gifford and Revitt 2010; Gifford et al. 2011; Holden et al. 2011; Spahr and Dorman 2005; Spahr et al. 2007) there has not yet been a systematic review of the effect of changing individual parameters and possible interactions between parameters on speech perception.

Vaerenburg et al. (2014) conducted a global survey of CI programming by collating the responses of $47 \mathrm{CI}$ centres. They reported the results of an inventory of worldwide clinical programming practice for 2013-14, which revealed the most frequently adjusted programmable parameters for all four CI manufacturers, including Cochlear Ltd, Med-El, Advanced Bionics and Neurelec. The decision to change parameters was reported to be guided by the individual preference of CI centres, CI manufacturer defaults and the adjustable parameters available within each manufacturer's device fitting software. All centres focused 
primarily on the adjustment of the minimum and maximum stimulating current level, which defines the electrical dynamic range (EDR). Reduction of the total number of stimulating electrodes was also a common parameter change, reported in approximately $10-15 \%$ of cases. Reasons provided for deactivation of electrodes included abnormal impedances, extracochlear location, non-auditory effects or noisy auditory perception. However, it was noted that electrodes were never reported to be disabled because of speech perception performance.

Within the Cochlear Ltd device, microphone input sensitivity can be set either as an automatic sensitivity control (ASC) or as fixed constant input sensitivity. ASC in the Cochlear Ltd device automatically adjusts the input sensitivity dependent upon estimates of the relative levels of speech and noise in the incoming signal, with the goal of enhancing the speech signal and the fixed constant allows a pre-set microphone sensitivity to be programmed. For the Med-El device, the parameters which affect input sensitivity were adjusted in 11-14\% of cases; for the Advanced Bionics device, sensitivity was adjusted in $4 \%$ of cases and for users of the Neurelec device, sensitivity was never adjusted.

Vaerenburg et al. (2014) reported sensitivity to be adjusted infrequently in clinical practice and when consideration was given to adjustment of the number of stimulating electrodes, this was indicated to be unrelated to speech perception at least in clinical practice. Where adjustment of the number of stimulating electrodes has been explored in research (Bierer and Faulkner 2010; Zhou 2017; Noble et al. 2016), there remains no consensus regarding methodology. Therefore, adjustment to sensitivity and to the number of stimulating electrodes have been considered to fall outside the remit of this review and have been excluded.

This systematic review will explore the effects on speech perception ability of adjustment to the following three parameters: (i) the input dynamic range (IDR), the range of 
acoustic sound levels that are mapped into the EDR; (ii) the electrical stimulation threshold (T) level, for each electrode, the level of electrical stimulation mapped to the lowest level of the IDR; (iii) the rate of electrical stimulation per electrode.

IDR and $\mathrm{T}$ level have been selected for review as these parameters are commonly adjusted at initial device activation and influence the processing of soft intensity sound toward the lower boundary of the EDR. Electrical stimulation rate has been selected, as this parameter can be adjusted across a wide range, but limited programming guidance about achieving an optimal setting for speech perception is available. Speech perception outcomes have been limited to clinical measures of speech perception, including vowel and consonant identification, monosyllabic word tests in quiet and in noise and open set sentence tests in quiet and in noise. The intention of the review is to determine clinical recommendations for CI programming.

\section{Brief overview of CI signal processing:}

While there are many common features within the signal processing approaches used by different commercial manufacturers of CI systems, there remain distinctions with system design rationale and implementation. Consequently, differences exist in the terminology used by CI manufacturers to describe such features and their application within respective clinical programming software.

Processing an acoustic input to an electrical output requires transduction of a large acoustic input range of approximately $90 \mathrm{~dB}$ to a relatively narrow EDR, typically between 6dB to $15 \mathrm{~dB}$ (Fu and Shannon, 2000). To achieve this, CI manufacturers use two methods: an automatic gain control (AGC) circuit, which applies non-linear compression to the acoustic input, and a sensitivity control, which adjusts the microphone input gain and can be applied in either a fixed or adaptive mode. These two methods can be applied either in isolation or in 
combination prior to transformation from the acoustic to the electrical signal domain. The minimum level of acoustic input captured is approximately $25 \mathrm{~dB}$ SPL, which is analogous to the noise floor of the electronic system. Potential exposure of the CI user to an audible noise floor is further limited using default first-fit parameters which are offered by all manufacturers and which are often supplemented with passive warnings within programming software. The maximum electrical output is limited for all CI manufacturers using output limiting compression. For Cochlear Ltd and Med-El, output compression will limit electrical stimulation at a perceptual level of loud, but comfortable, which is labelled as C level or maximum comfort level (MCL) and set within clinical software. For Advanced Bionics and Neurelec, the limit to electrical stimulation will occur at a perceptual comfort level or M level set within the clinical software, with an additional stimulus range programmed within the upper volume control range applied as a percentage increase of the entire EDR. Output limiting compression applies a very high compression ratio above a fixed or programmable value, preventing stimulation above this value. The use of output limiting compression prevents overstimulation and ensures electrical transduction of an optimal acoustic signal range for the presentation of speech sounds.

IDR refers to the range of acoustic input post-attenuation by either an automatic gain control (AGC) or an ASC circuit. Instantaneous input dynamic range (IIDR) refers to the range of short-term acoustic fluctuations, which are instantaneously captured without the application of AGC or ASC and this term is used as a descriptor only for devices produced by Cochlear Ltd. Despite differences in terminology and in position within the electrical circuit, IDR and IIDR fundamentally describe the size of the input acoustic signal. IIDR adjustment within the Cochlear Ltd system is achieved by setting T-SPL and C-SPL. Within the fitting software, T-SPL is the input sound pressure level (SPL) where the implant starts to stimulate at T-level and C-SPL the input SPL where output limiting compression starts. Studies 
reporting IDR adjustment were conducted using the Advanced Bionics system where IDR is an adjustable parameter within the clinical fitting software. No studies reporting adjustment for the Med-El or Neurelec systems were found, as these both have a fixed IDR.

Manufacturer terminology for $\mathrm{T}$ level is consistent for all CI manufacturers, where this represents the threshold of electrical stimulation and the lowest level of the EDR. Of note however, Cochlear Ltd, Med-El and Neurelec do not provide electrical stimulation below the setting of T level in default settings offered within their respective clinical software. In contrast, the Advanced Bionics device continues electrical stimulation below the setting of $\mathrm{T}$ level, despite T level representing an electrical value corresponding to perceptual hearing threshold. Therefore, the stimulus is likely inaudible to a CI user, particularly where the audible hearing threshold is configured accurately.

Electrical stimulation rate can be adjusted within all commercial CI systems. Stimulation rate refers to the number of electrical pulses delivered to each electrical contact per second; affecting the coding of information in the time domain. Rate per contact is capped by the overall system update rate, which is divided to multiple electrical outputs, either directly to an active electrical contact or indirectly through use of virtual current steering.

\section{Method:}

The systematic review was conducted in accordance with guidance published by the Centre for Reviews and Dissemination (2009). The research question has been derived using the population, intervention, comparators, objectives and study design (PICOS) methodology.

\section{PICOS question:}

In CI users, are adjustments of IDR, T level and rate of electrical stimulation, compared to manufacturer defaults, effective in improving speech perception? 
The literature search considered studies where changes were made to the programmable parameters of IDR, T level and stimulation rate with a speech perception outcome. To extract research publications for review, each parameter was searched in combination with both "Cochlear Implant" and "Speech perception". The electronic databases searched included MEDLINE and EMBASE and the databases were searched from the start date for each database up until $2^{\text {nd }}$ January 2016, without language restriction. Figure 1 indicates key words used in the search fields.

Figure 1.

Figure 2 provides a flow chart of the primary search and inclusion process. In the primary search 242 studies were identified; these were stratified into 112 studies describing T level setting, 12 studies describing IDR setting and 118 describing stimulation rate setting. Following review of the title and abstract, 197 studies were excluded. A total of 45 studies were reviewed in full and a further 13 were excluded as they failed to meet the following extended criteria:

(1) an experimental study using human subjects; not an animal model

(2) IDR, (T) level or stimulation rate a key independent variable in the experimental design

(3) a standardised speech perception measurement used to define the outcome

Figure 2.

\section{Rating of Quality Evidence:}

Two evidence-based practice (EBP) review rating schemes were used to allocate levels of evidence scores to each of the studies (Tables 1-3). Firstly, using the criteria of the Oxford Centre for Evidence Based Medicine (OCEBM) Levels of Evidence (2011). The OCEBM (2011) methodology enables a heuristic or "rule of thumb" classification allowing clinicians 
and patients to answer clinical questions quickly and without resorting to pre-appraised sources. OCEBM provide a hierarchy with five levels of evidence, ranked by strength of evidence from Level 1 (highest) to Level 5 (lowest). Determination of the level score for each study applies a series of clinical questions, which consider the effect of treatment including benefit, harm and overall utility. Secondly, using the criteria of Valente et al. (2006) which also provide a five-point scale from Level 1 (highest) to Level 5 (lowest) for ranking studies according to strength of evidence and stratifying studies according to where evidence was measured. If evidence was measured in the "real world" it is described as Effective (EV), whereas evidence was measured under "laboratory or ideal" conditions, it is described as Efficacy (EF).

To determine level of evidence scores, independent detailed analysis of each article in full text was performed by two researchers; the first author (T.B.N) and the final author (D.A.V.). Any disagreement between the score determined was resolved by consensus.

\section{Study Quality assessment:}

The quality of studies was assessed through review of the following criteria. Missing data were accounted for, an appropriate analysis of the data was performed, confounding factors were reported and controlled for, appropriate outcome measures and controls were used, a power calculation was performed, eligibility criteria were clearly specified and ethical approval was gained.

Figure 3.

\section{Data synthesis:}

Significant heterogeneity existed in the methodology and experimental design of the studies which fulfilled the review criteria. Studies were conducted in multiple centres, speech test 
material was in five different languages, with the majority in a pre-recorded format except for a single study which used 'live' voice presentation.

The most common speech outcome measure was the CNC wordlist, which was used in 15 studies. Three studies used the Freiburg monosyllable test, 1 study used the NU-6 wordlist and 4 studies used non-standardised speech materials. Non-standard materials consisted of monosyllables presented in cocktail party noise, a disyllabic wordlist, a categorical speech perception task and a two-digit numerical perception task.

There was similar diversity using vowel and consonant perception tasks: of the 9 studies which utilised a specific vowel identification task (i.e. excluding vowel identification scores extracted from performance on the CNC wordlist), 7 used the $/ \mathrm{hVd} /$ context, 1 used the $/ \mathrm{bVb} /$ context and 1 used the $/ \mathrm{bVt} /$. Specific consonant identification tasks were used in 10 studies. There were 8 uses of the /aCa/ context, 2 uses of the /iCi/ context and 1 use of the leCe/ and $/ \mathrm{uCu} /$ contexts. Further analysis of the consonant features of manner of articulation, place of articulation and voicing were reported in 4 studies.

Sentence based speech perception material consisted of 9 standardised tests and 2 non-standardised tests recorded in four different languages. Sentences in noise used 5 different noise types and varied delivery by using either (i) a fixed signal to noise ratio (SNR) (ii) an adaptive procedure where speech level was fixed, but noise level was varied to determine a SNR at which speech recognition is at $50 \%$ correct, denoted as the speech reception threshold $\left(\mathrm{SRT}_{50}\right)$.

Study characteristics and outcomes have been tabulated to enable comparison. Where statistical analysis has provided a test outcome of significance, results have been included. To enable quantification, a statistical outcome of large significance refers to $p<0.001$, of medium significance refers to $\mathrm{p}<0.01$ and of small significance refers to $\mathrm{p}<0.05$. 


\section{Results:}

The inclusion criteria were met by 32 papers. A single paper assessed both T level and IDR setting and as adjustment to these parameters was made separately and the speech perception measured independently, the speech perception outcome has been included for both the T level and IDR setting change. Tables 1 to 3 provide details of the characteristics of studies for each of the parameter subsets of T level, IDR and stimulation rate.

Table 1.

Table 2.

Table 3.

\section{Quality of studies:}

Studies had a median sample size of 10 and a range from 3 to 150 . None contained a metaanalysis or were based on a randomised controlled trial (Figure 3). Only one study performed a power calculation and $36 \%$ of studies reported missing data. Reasons provided for missing data included being unavailable to complete all test sessions, withdrawal following side effects from the change in stimulation pattern or being functionally incapable of completing the speech test outcome measure. Subject selection criteria were well documented in $81 \%$ of studies, although confounding factors were either uncontrolled or only partially controlled in $25 \%$ of papers; a specific example of which was the accounting and controlling for aetiologies with a known neuro-degenerative component or with an abnormal cochlear anatomy. The method of statistical analysis varied widely across studies, precluding statistical comparison of data. For all studies, subjects served as their own control and in thirteen studies a crossover design was employed to assess and quantify experimental order and learning effects. 
From the EBP rating schemes, 3 studies were rated as OCEBM level 2 due to the use of randomisation within their design, 26 studies achieved level 3 and 3 achieved level 4 . Using the Valente rating scale, 31 studies were at level 3; 1 was at level 4 and 12 of the 32 provided 'real life' listening experience following the parameter change. On this basis, the quality of studies was determined to be moderate to poor.

Table 4.

\section{T level adjustment:}

Eight studies explored the impact of adjustment to measured $\mathrm{T}$ level. $\mathrm{T}$ level is the level of electrical stimulation mapped to the lowest level of the IDR and a behavioural response at the threshold of audible detection to an electrical stimulus. Recommended methods for setting T level differ across manufacturers and devices. However, the methods reported in the eight studies which examined a departure from default advice, followed the following four approaches:

- setting the T level higher than measured perceptual threshold, to a perceptual loudness rating between very soft to medium or barely audible to soft.

- setting $\mathrm{T}$ at $10 \%$ of the $\mathrm{M}$ level (M level representing the maximum programmed stimulus level and the upper limit of the EDR)

- $\quad$ setting $\mathrm{T}$ level at a percentage of the EDR.

- $\quad$ setting $\mathrm{T}$ level at $0 \mu \mathrm{A}$

Monosyllable tests in quiet were reported in two studies. No significant change to monosyllable perception was reported when T level was set at 10\% of M (Tanamati et al. 2005). A significant, but small improvement was reported for elevating $\mathrm{T}$ level to a loudness rating of very soft to medium (Skinner et al. 1999). Similarly, Skinner et al. (1999) also found 
that this adjustment produced a significant, but small improvement in phoneme perception. Vowel and consonant perception reported in two studies indicated either no difference when comparing behavioural T, T at $10 \%$ of $\mathrm{M}$ or $\mathrm{T}$ at $0 \mathrm{uA}$ (Spahr and Dorman 2005) or a small significant improvement for vowels and consonants with $\mathrm{T}$ set to a higher value within the EDR (Fu and Shannon 2000). Sentences in quiet, reported in four studies, indicated no change for $\mathrm{T}$ at $10 \%$ of $\mathrm{M}$ or for $\mathrm{T}$ at $0 \mu \mathrm{A}$ (Boyd 2006; Spahr and Dorman 2005; Tanamati et al. 2005) and a medium and a large significant improvement for elevated $\mathrm{T}$ at levels corresponding to a perceptual loudness rating of very soft to medium for sentences presented at 70dBSPL and 50dB SPL respectively (Skinner et al. 1999). Sentences in noise, reported in three studies indicated no change (Spahr and Dorman 2005; Tanamati et al. 2005) for T at $10 \%$ of $\mathrm{M}$ or $\mathrm{T}$ at $0 \mu \mathrm{A}$ and a small significant improvement in perception (Zhou and Pfingst 2014) for a T level elevated as a percentage of the EDR.

\section{IDR adjustment:}

Eight studies reviewed the outcome of a change to IDR. No studies explored IDR adjustment for the Neurelec or Med-El devices. Neurelec use a fixed IDR of $75 \mathrm{~dB}$ and Med-El a roving $55 \mathrm{~dB}$ sound window, adapted by an AGC circuit. For studies using the Cochlear Ltd device, instantaneous input dynamic range or IIDR is reported, which for the current Cochlear N6 speech processor applies a default IIDR value of 40dBSPL. In Advanced Bionics devices, the default of 60dB IDR will capture acoustic signals from 25dB SPL to 85dB SPL. If the IDR is decreased this will restrict the acoustic input translated to the lower end of the electrical dynamic range, e.g. a 40dB IDR would correspond to acoustic levels between 45 and $85 \mathrm{~dB}$ SPL. Conversely, an increased IDR of $70 \mathrm{~dB}$ would translate acoustic levels between 25 to 95 dB SPL to the electrical domain. 
Monosyllable perception tests were reported in four studies. Holden et al. (2011) reported a medium significant improvement for an IDR of 65 and $80 \mathrm{~dB}$ compared to $50 \mathrm{~dB}$ and three studies which reported a large significant improvement in perception for an IIDR of 40dB compared to 30dB (Davidson et al. 2007; Holden 2007) and for 46dB and 56dB compared to 31dB (Dawson et al. 2007).

Phoneme perception showed a large significant improvement for an IIDR of 40dB compared to $30 \mathrm{~dB}$ (Holden et al. 2007). Vowel perception was reported in four studies; Holden et al. (2007) and James et al. (2003) found no significant change, but Dawson et al. (2007) reported a large significant improvement in perception for an IIDR of 48dB and 56dB compared with an IIDR of $31 \mathrm{~dB}$. Zeng et al. (2002) reported a medium significant improvement for IDRs of 40, 50 and 60dB when compared to narrower levels. Of note, Zeng et al. (2002) presented vowels in speech shaped noise at $+5 \mathrm{~dB}$ SNR rather than in quiet. This was the only example of a study investigating IDR using a test condition with noise.

Consonant perception was reported in four studies. James et al. (2003) and Zeng et al. (2002) reported a medium significant improvement in perception when comparing an IIDR of $30 \mathrm{~dB}$ to an IIDR of either $38 \mathrm{~dB}$ or $41 \mathrm{~dB}$ and for an IDR of $50 \mathrm{~dB}$ and $60 \mathrm{~dB}$ compared to an IDR of 40dB or less. A large significant improvement was reported for two studies which compared an IIDR of $46 \mathrm{~dB}$ and 56dB with an IIDR of 31dB (Dawson et al. 2007) and which compared an IIDR of $40 \mathrm{~dB}$ to that of $30 \mathrm{~dB}$ (Holden et al. 2007).

Sentences in quiet were reported in three studies. No change (Holden et al. 2007) or a small significant decrease in perception (Veekmans et al. 2010) were reported when comparing IIDR expansion from $30 \mathrm{~dB}$ to $40 \mathrm{~dB}$ and $30 \mathrm{~dB}$ to $50 \mathrm{~dB}$ respectively. Spahr et al. (2007) indicated a small significant improvement for IDRs of 50dB and $60 \mathrm{~dB}$ when compared to and IDR of $30 \mathrm{~dB}$. 
Sentences in noise were reported in seven studies. James et al. (2003) indicated a medium significant decrement in speech-in-noise perception using BKB sentences presented at $65 \mathrm{~dB}$ SPL in eight talker-babble with a SNR chosen to produce a keyword correct score of greater than $35 \%$, but less than $70 \%$ when expanding IIDR from $30 \mathrm{~dB}$ to $38 \mathrm{~dB}$. Three studies indicated no significant change to perception; Davidson et al. (2009) for sentences presented at $65 \mathrm{~dB}$ SPL using four talker-babble with SNR at SRT when expanding IIDR from 30 to 40dB; Dawson et al. (2007) for sentences presented at 65dB SPL using eight talker-babble with subject specific SNR when expanding IIDR from 30 to 40dB and Holden et al. (2011) for sentences presented at 65dB SPL using eight talker-babble with subject specific SNR when expanding IDR from 50 to 65 to $80 \mathrm{~dB}$.

Three studies reported a small, but significant improvement to perception. Veekmans et al. (2010) for sentences presented at 60dBA with noise at $+5 \mathrm{~dB}$ SNR, when expanding IIDR from 30 to 50dB; Holden et al. (2007) for sentences 65dBSPL in eight talker-babble at user specific SNR when expanding IIDR from 30 to 40dB and Spahr et al. (2007) using speech presented at $77 \mathrm{dBSPL}$ at $+10 \mathrm{~dB}$ SNR for IDR wider than $30 \mathrm{~dB}$.

\section{Stimulation rate adjustment:}

The range of stimulation rates tested across the seventeen studies was from 250pps/e to 5158pps/e.

There were eight studies exclusively reporting changes in stimulation rate for the Cochlear Ltd device, three which used the Advanced Bionics device, four which used the Med-El device, one which used the Neurelec device and one which used both the Cochlear Ltd and Advanced Bionics devices. Data is plotted in Figure 4 (monosyllabic word tests), Figure 5 (sentences in quiet) and Figure 6 (sentences in noise). Rates which provided a statistically significant increase in speech perception compared to at least some of the other rates tested 
are highlighted in grey. Instances in which a higher rate produced a statistically significant decrease in speech perception are highlighted in black. Studies which showed no significant effect of change in rate have not been plotted but these are included in Table 4.

Figure 4

Figure 5

Figure 6

Figure 4 shows significant change to monosyllable perception and rate change for five studies, of which two used the Med-El device, one the Advanced Bionics, one the Cochlear Ltd and one the Neurelec device. Differences exists for the mode of monosyllabic word presentation, test level used and test material language for the reviewed studies, as described in Table 3. Park et al. (2012) used recorded monosyllabic material presented at 45dBHL, Loizou et al. (2000) used a direct input signal to a research processor at each subject's comfortable listening level and Buechner et al. (2010) gave no detail for the mode or intensity level for presentation.

Four from five studies reported improved monosyllabic word perception with increased rate, although this improvement did not continue for all higher rates examined. However, a decrement in monosyllabic word perception was reported by Park et al. (2012). Specific characteristics, which may have influenced the degraded response include the low monosyllable presentation intensity selected of $45 \mathrm{dBHL}$, the single large step in rate change of 2.7 times the lower standard rate or the method of signal processing used within the Cochlear Ltd device. 
Figure 5 plots sentence in quiet perception and rate change for two studies using the Advanced Bionics and Neurelec devices. CID sentences were presented at 70dB SPL in 'live voice' (Di Lella et al. 2010). HSM sentences were used, but no detail for the mode or intensity level for presentation was provided for (Buechner et al. 2010). Both studies report a moderate significant improvement in sentence perception for a higher stimulation rate, but the interpretation of this outcome is limited by study design and an absence of experimental detail.

Figure 6. plots sentence in noise perception and rate change for six studies of which four used the Cochlear Ltd device, one the Advanced Bionic and one Neurelec. Limited consistency existed for the mode and presentation level of sentences in noise. (Arora et al. 2011; Battmer et al. 2010) used a stimulus level of 65dBSPL, calculating an $\mathrm{SRT}_{50}$, that is a SNR ratio when $50 \%$ of the sentences are correctly perceived. However, these studies differed by sentence material, language and noise type. Di Lella et al. (2010) and Vandali et al. (2000) used a stimulus intensity of 70dBSPL at either a single fixed SNR of $+10 \mathrm{~dB}$ or at three fixed steps between 0 and $+20 \mathrm{~dB}$ SNR, which were described as low, medium and high SNR levels. However, these differed by sentence material, language and mode of presentation; live voice versus recorded.

Holden et al. (2002) tested at three intensities of 50,60 and 70dBSPL using subject specific fixed SNR, which provide a correct perception score of between $30 \%$ and $75 \%$. No detail for the mode or presentation intensity level was provided for Buechner et al. (2010), although confirmation of a $+10 \mathrm{~dB}$ SNR was given.

Four from six studies reported improved sentence in noise perception with increased rate, although this improvement did not continue for all higher rates examined. A decrement in sentence in noise perception was reported in two studies, Battmer et al. (2010) reported a small significant decrement in speech in noise perception for a rate of 3500pps/e when 
compared to 500pps/e and 1200pps/e and Vandali et al. (2000) reported a medium and large significant decrement in speech in noise perception for $1615 \mathrm{pps} / \mathrm{e}$ when compared to 807pps/e and 250pps/e for the middle and lowest SNR tested.

Battmer et al. (2010) reported a potential confounding factor in his study, which was the presence of stimulation rate bias; some study subjects had used a 1200pps/e stimulation rate for 13-33 weeks prior to enrolment.

Vandali et al. (2000) indicated a large significant interaction between subject and rate, for the middle and lowest SNR tested, indicating the speech-in-noise perception scores varied from subject to subject with rate of stimulation. Consequently, the authors further evaluated the influence of individual subject variance and reported that the significantly lower group mean scores obtained with the $1615 \mathrm{pps} / \mathrm{e}$ compared with those of the two lower stimulation rates evaluated could be accounted for predominantly by the results of a single subject.

\section{Complications:}

The adjustment of $\mathrm{T}$ level, IDR and stimulation rate provided a reported complication in three studies. Holden et al. (2011) used the Advanced Bionics device and increased T level by raising this above perceptual hearing threshold to a level which provided a loudness rating of barely audible and very soft; they then compared three IDR levels of 50, 65 and $80 \mathrm{~dB}$. They reported that four subjects experienced a static-like noise in quiet with raised $\mathrm{T}$ levels and an increased IDR. Further exploration defined this to be system noise, which could be traced to the input microphone. Holden et al. (2002) and Vandali et al. (2000) evaluated change to rate of electrical stimulation in the Cochlear Ltd N24 device. Both authors reported subjects who experienced severe tinnitus when using a map with a higher rate of stimulation and in each case, the participants withdrew from the study. 


\section{Discussion:}

\section{Is speech perception improved by increasing T level?}

Increasing $\mathrm{T}$ levels when programming a CI has the effect of improving the audibility of soft intensity sound by increasing corresponding electrical current stimulation.

From the reviewed papers, only Skinner et al. (1999) compared setting T level at a perceptual audible threshold with $\mathrm{T}$ levels raised to perceptual level which provides a loudness rating of very soft or medium using a speech perception outcome. For users of the Cochlear Ltd N22 system utilising presentation intensities of 50, 60 and 70dB SPL for both CNC monosyllables and CUNY sentences, they reported a medium significant improvement for monosyllable perception at 50 and 60dB SPL, but no change for 70dB SPL and a large significant improvement for sentences presented at 50dBSPL and a small significant improvement at 70dBSPL.

A significant change in sentence perception in noise following an increase to T level was reported only for Cochlear Ltd N24 users (Zhou and Pfingst 2014). Modulation detection thresholds (MDT) at 50\% of the EDR were used to define five channels with the poorest averaged modulation sensitivity. Channels with poor MDT had an applied increase to T level of either 5 or $10 \%$ of the DR. SRTs were measured using the original T level map, where T was set to a perceptual hearing threshold; a T level plus 5\% DR map and T level plus 10\% DR map. A small significant improvement in $\mathrm{SRT}_{50}$ for the T level plus 5\% DR map was reported, which supports a more precise adjustment of individual channel parameters to improve recognition of speech in noise.

Increasing $\mathrm{T}$ levels in the Cochlear Ltd device either above perceptual behavioural level or as a proportion of the EDR has been reported to provide benefit to monosyllable perception for presentation at 50dB and 60dBSPL and for sentences in quiet at 50dBSPL. 
Increasing $\mathrm{T}$ levels of specific electrodes with a poor MDT in the Cochlear Ltd N24 device provided an improved SRT for sentences presented at 60dBA in modulated noise.

For the Med-El, Advanced Bionics and Neurelec device, no studies examined the influence on speech perception ability using a method to effectively increase the setting of $\mathrm{T}$ level.

\section{Is speech perception improved by increasing IDR?}

The dynamic range of speech and the implication for optimal conversion to an auditory electrical stimulation pattern in CI has been investigated (Zeng et al. 2002). They evaluated the acoustic dynamic range of consonants and vowels with both acoustic broadband and narrowband analyses which provided an approximate distribution of speech envelope levels of $50 \mathrm{~dB}$. They then evaluated IDR change in steps of $10 \mathrm{~dB}$ from $10 \mathrm{~dB}$ to $80 \mathrm{~dB}$ for Advanced Bionics CI users using vowels and consonants in quiet and in noise; this indicated speech perception to be optimal at a 50-60dB IDR. Despite a large variability in phoneme perception in noise, the use of a slightly narrower IDR provided improved recognition which derived from consonant recognition. Except for Veekmans et al. (2010) for the Cochlear Ltd device, perception of either monosyllables or sentences in quiet, remain unchanged or improve with a wider IIDR greater than $30 \mathrm{~dB}$. Speech in noise is reported to benefit from a narrower IIDR (James et al. 2003), but this contrasts with Davidson et al. (2009) and Dawson et al. (2007) who indicate no change and Veekmans et al. (2010) and Holden et al. (2007) who report a small significant improvement with a wider IIDR of $40 \mathrm{~dB}$. It must be considered that a significant interaction with the sensitivity parameter occurs in the Cochlear Ltd device, which cannot be viewed in isolation when examining the effect of IIDR.

The effect of IDR/IIDR expansion varied for the studies reviewed. The lack of consistency is influenced by several factors which include, the different methodology 
employed by each manufacturer when translating an IDR into to an EDR, the wide variety of speech perception test materials used in studies, the reported between subject variability and the differing periods of adaptation afforded to subjects prior to measurement of speech perception.

In the Cochlear Ltd device, monosyllable and consonant recognition for soft intensity speech presented between 45dBSPL and 55dBSPL improved with an IIDR increase to either $40 \mathrm{~dB}$ or $46 \mathrm{~dB}$. An IIDR of $40 \mathrm{~dB}$ is the current default within the latest Cochlear Ltd fitting software (Custom Sound® v5.0).

In the Advanced Bionics device, a range of IDR between 65 to $80 \mathrm{~dB}$ can be used to optimally perceive monosyllables in quiet, however any expansion above $65 \mathrm{~dB}$ should be evaluated for an audible noise floor and consequently should be offered to CI users in the clinical setting who are able to provide feedback. For speech in noise an IDR of 50dB provided optimal outcomes. An IDR of $60 \mathrm{~dB}$ is the current default within the latest Advanced Bionics fitting software (SoundWave ${ }^{\mathrm{TM}} \mathrm{v} 3.1$ ).

\section{Is speech perception improved by increasing stimulation rate?}

Default stimulation rates offered by current CI devices at initial activation, assuming all electrodes are useable following a full intra-cochlear insertion, range from 1040pps/e for the Oticon Medical device (formerly the Neurelec system) to approximately 2700pps/e, which can be commonly found in the Advanced Bionics and Med-El devices.

Studies that evaluated rate of stimulation explored a range of stimulation rates which due to the use of older CI devices led to a more frequent exploration of slower stimulation rates than those offered as default in current CI devices. Due to differences in CI manufacturer system design, CI systems provide individual and contrasting range of stimulation rates. Speech perception outcomes were therefore reviewed by individual CI 
manufacturer and stimulation rate. However, no clear effect upon speech perception when using an increased electrical stimulation rate by manufacturer could be established.

For electrical stimulation rate, no clear guidance can be defined as different rates will often provide a significant across subject variation in speech perception outcome, which in some cases can be so large as to cause a deviation from group mean trends (Keifer et al. 2000). An optimal stimulation rate is therefore likely to be specific to each subject.

\section{Limitation of Systematic review:}

The quality of studies included within the review was moderate to poor. As no randomised trials exist within the review, selection bias must be assumed to be a confounding factor in the outcomes reported. The adaptation period provided from parameter change to speech perception testing ranged from 5 minutes to 24 weeks with a median period of 3.5 hours. When evaluating the effect of a parameter change with a sentence perception task in quiet or in fixed or adaptive noise, any increase to available speech perception cues may require a period of adaptation (Svirsky et al. 2015). Consolidation of new or changed speech cues to the perception of sentences over time can be protracted and vary across subjects, which is unlikely to be conducive to measuring change in an acute or chronic test design. The heterogeneity of subject selection, study design, test materials and languages limit the utility of the review to inform clinical practice or make recommendation.

Significant heterogeneity existed within the reviewed studies, preventing metaanalysis. However, the complications observed and reported in two studies may assist to inform future studies of possible expected adverse events providing more complete and robust information to potential study participants at recruitment. The inclusion of all CI manufacturers may have added complexity to the review as manufacturers utilise differing 
techniques in signal processing and may or may not offer a method to manipulate all parameters.

\section{Conclusion:}

Adjustment of T level, IDR and stimulation rate within heterogeneous groups has led to a high variability in outcomes. The limited consistency in experimental design across multiple languages using differing test materials and afforded adaptation and follow up, further complicates the utility of the review for quantifying trends or provide clinical recommendation. Despite these limitations, the following can be defined:

(1) T levels above behavioural threshold or as proportion of EDR has been demonstrated to improve perception of monosyllables in quiet and sentences in both quiet and in noise.

(2) the use of wider IIDR/ IDR setting can improve perception of monosyllables in quiet, particularly at softer presentation intensity. The use of wider IIDR/ IDR setting for sentences in quiet and in noise provide mixed outcomes, which would necessitate a systematic evaluation if applied clinically.

(3) no recommendation could be determined for rate of stimulation as speech perception varied significantly across the stimulation rates examined.

Although manufacturer defaults for parameter settings, provide a useful first setting, they may not provide the most effective setting. This is acknowledged to contribute to the significant across subject variability for speech perception reported in the review. Consequently, a prevailing recommendation is for bespoke parameter settings to be applied to individual subjects. Further research to provide recommendations for configuration of individual settings remains a challenge. However, to define an individualised configuration will ensure optimal device mapping and the most advantageous setting for speech perception 
across a variety of intensities, in quiet and in competing noise.

Acknowledgements:

The authors are grateful to Alex Stagg for his guidance on the research database search strategy.

Disclosure:

In accordance with Taylor \& Francis policy and my ethical obligation as a researcher, I am reporting that I declare no potential conflicts of interests with respect to the authorship and publication of this article. 


\section{References:}

Arora, K., A. Vandali, R. Dowell, and P. Dawson 2011. Effects of stimulation rate on modulation detection and speech recognition by cochlear implant users. International Journal of Audiology 50, no 2: 123-32.

Balkany, T., A. Hodges, C. Menapace, L. Hazard, C. Driscoll, B. Gantz, D. Kelsall et al. 2007. Nucleus freedom North American clinical trial. Otolaryngology Head \& Neck Surgery 136, no 5: 757-62.

Battmer, R.D., N. Dillier, W.K. Lai, K. Begall, E.E. Leypon, J.C. Gonzalez, M. Manrique et al. 2010. Speech perception performance as a function of stimulus pulse rate and processing strategy preference for the cochlear nucleus CI24RE device: Relation to perceptual threshold and loudness comfort profiles. International Journal of Audiology 49, no 9: 657-66.

Baudhuin, J., J. Cadieux, J.B. Firszt, R.M. Reeder, and J.L. Maxson 2012. Optimization of programming parameters in children with the advanced bionics cochlear implant. Journal of the American Academy of Audiology 23, no 5: 302-12.

Bierer, J.A. and K.F. Faulkner 2010. Identifying cochlear implant channels with poor electrode-neuron interface: Partial tripolar, single-channel thresholds and psychophysical tuning curves. Ear \& Hearing 31, no 2: 247-58.

Blamey, P., F. Artieres, D. Başkent, F. Bergeron, A. Beynon, E. Burke, N. Dillier et al. 2013. Factors affecting auditory performance of postlinguistically deaf adults using cochlear implants: An update with 2251 patients. Audiology \& Neurotology 18, no 1: 36-47.

Bonnet, R.M., P.B.M. Boermans, O.F. Avenarius, J.J. Briaire and J.H. Frijns 2012. Effects of pulse width, pulse rate and paired electrode stimulation on psychophysical measures of dynamic range and speech recognition in cochlear implants. Ear \& Hearing 33, no 4: 489-96.

Boyd, P.J. 2006. Effects of programming threshold and maplaw settings on acoustic thresholds and speech discrimination with the med-el combi 40+ cochlear implant. Ear \& Hearing 27, no 6: 608-18.

Boyle, P.J., T.B. Nunn, A.F. O'Connor, and B.C.J. Moore 2013. STARR: A speech test for evaluation of the effectiveness of auditory prostheses under realistic conditions. Ear \& Hearing 34, no 2: 203-12.

Brill, S.M., W. Gstottner, J. Helms, C. Von Ilberg, W. Baumgartner, J. Muller and J. Kiefer 1997. Optimization of channel number and stimulation rate for the fast continuous 
interleaved sampling strategy in the combi 40+. American Journal of Otology 18, no 6 Suppl.

Buechner, A., C. Frohne-Buchner, L. Gaertner, T. Stoever, R.D. Battmer, T. Lenarz 2010. The advanced bionics high resolution mode: Stimulation rates up to $5000 \mathrm{pps}$. Acta Oto Laryngologica 130, no 1: 114-23.

Davidson, L.S., M.W. Skinner, B.A. Holstad, B.T. Fears, M.K. Richter, M. Matusofsky, C. Brenner et al. 2009. The effect of instantaneous input dynamic range setting on the speech perception of children with the nucleus 24 implant. Ear \& Hearing 30, no 3: $340-9$.

Dawson, P.W., A.E. Vandali, M.R. Knight and J.M. Heasman 2007. Clinical evaluation of expanded input dynamic range in nucleus cochlear implants. Ear \& Hearing 28, no 2: 163-76.

Di Lella, F., A. Bacciu, E. Pasanisi, V. Vincenti, M. Guida and S. Bacciu 2010. Main peak interleaved sampling (MPIS) strategy: Effect of stimulation rate variations on speech perception in adult cochlear implant recipients using the Digisonic SP cochlear implant. Acta Oto Laryngologica 130, no 1: 102-7.

Centre for Reviews and Dissemination, 2009. Systematic reviews: CRD's Guidance for undertaking reviews in Healthcare. University of York.

Donaldson, G.S., T.H. Chisolm, G.P. Blasco, L.J. Shinnick, K.J. Ketter and J.C. Krause 2009. BKB-SIN and ANL predict perceived communication ability in cochlear implant users. Ear \& Hearing 30, no 4: 401-10.

Friesen, L.M., R.V. Shannon and R.J. Cruz 2005. Effects of stimulation rate on speech recognition with cochlear implants. Audiology \& Neuro Otology 10, no 3: 169-84.

Fu, Q.J. and Shannon R.V. 2000. Effects of dynamic range and amplitude mapping on phoneme recognition in nucleus-22 cochlear implant users. Ear \& Hearing 21, no 3: 227-35.

Gifford, R.H., A.P. Olund and M. Dejong 2011. Improving speech perception in noise for children with cochlear implants. Journal of the American Academy of Audiology 22, no 9: 623-32.

Gifford R.H. and L.J. Revit. 2010. Speech perception for adult cochlear implant recipients in a realistic background noise: Effectiveness of preprocessing strategies and external options for improving speech recognition in noise. Journal of the American Academy of Audiology 21, no 7: 441-51; quiz 87-8. 
Howick, J., I. Chalmers, P. Glasziou, T. Greenhalgh, C. Heneghan, A. Liberati, I. Moschetti, B. Phillips and H. Thornton 2011. The 2011 Oxford CEBM Evidence Levels of Evidence (Introductory Document). Oxford Centre for Evidence-Based Medicine. http://www.cebm.net/index.aspx?o=5653

Holden, L.K., R.M. Reeder, J.B. Firszt, C.C. Finley 2011. Optimizing the perception of soft speech and speech in noise with the advanced bionics cochlear implant system. International Journal of Audiology 50, no 4: 255-69.

Holden, L.K., M.W. Skinner, M.S. Fourakis and T.A. Holden 2007. Effect of increased IIDR in the nucleus freedom cochlear implant system. Journal of the American Academy of Audiology 18, no 9: 777-93.

Holden, L.K., M.W. Skinner, T.A. Holden and M.E. Demorest 2002. Effects of stimulation rate with the nucleus 24 ace speech coding strategy. Ear \& Hearing 23, no 5: 463-76.

James, C.J., M.W. Skinner, L.F. Martin, L.K. Holden, K.L. Galvin, T.A. Holden, L. Whitford 2003. An investigation of input level range for the nucleus 24 cochlear implant system: Speech perception performance, program preference, and loudness comfort ratings. Ear \& Hearing 24, no 2: 157-74.

Kiefer, J., C. Von Ilberg, V. Rupprecht, J. Hubner-Egner and R. Knecht 2000. Optimized speech understanding with the continuous interleaved sampling speech coding strategy in patients with cochlear implants: Effect of variations in stimulation rate and number of channels. Annals of Otology, Rhinology \& Laryngology 109, no 11: 100920.

Loizou, P.C., O. Poroy and M. Dorman 2000. The effect of parametric variations of cochlear implant processors on speech understanding. Journal of the Acoustical Society of America 108, no 2: 790-802.

Nie, K., A. Barco, F.G. Zeng 2006. Spectral and temporal cues in cochlear implant speech perception. Ear \& Hearing 27, no 2: 208-17.

Noble, J.H., A.J. Hedley-Williams, L. Sunderhaus, B.M. Dawant, R.F. Labadie, S.M. Camarata and R.H. Gifford 2016. Initial results with image-guided cochlear implant programming in children. Otology and Neurotology 37, no 2: e63-e69.

Park, S.H., Kim E., Lee H.J. and Kim H.J. 2012. Effects of electrical stimulation rate on speech recognition in cochlear implant users. Korean Journal of Audiology 16, no 1: 6-9. 
Plant, K., L. Holden, M. Skinner, J. Arcaroli, L. Whitford, M.A. Law and E. Nel 2007. Clinical evaluation of higher stimulation rates in the nucleus research platform 8 system. Ear \& Hearing 28, no 3: 381-93.

Plant, K.L., L.A. Whitford, C.E. Psarros, A.E. Vandali 2002. Parameter selection and programming recommendations for the ACE and CIS speech-processing strategies in the Nucleus 24 cochlear implant system. Cochlear Implants International 3, no 2: 104-25.

Shannon, R.V., R.J. Cruz and J.J. Galvin 3rd 2011. Effect of stimulation rate on cochlear implant users' phoneme, word and sentence recognition in quiet and in noise. Audiology \& Neurotology 16, no 2: 113-23.

Skinner, M.W., L.K. Holden, T.A. Holden and M.E. Demorest 1999. Comparison of two methods for selecting minimum stimulation levels used in programming the nucleus 22 cochlear implant. Journal of Speech Language \& Hearing Research 42, no 4: 81428.

Spahr, A.J., M.F. Dorman, L.H. Loiselle 2007. Performance of patients using different cochlear implant systems: Effects of input dynamic range. Ear \& Hearing 28, no 2: 260-75.

Spahr, A.J. and M.F. Dorman 2005. Effects of minimum stimulation settings for the Med-El Tempo+ speech processor on speech understanding. Ear \& Hearing 26, no 4 Suppl.

Svirsky, M.A., T.M. Talavage, S. Sinha, H. Neuburger and M. Azadpour 2015. Gradual adaptation to auditory frequency mismatch. Hearing Research 322: 163-70.

Tanamati, L.F., L.T. Do Nascimento and M.C. Bevilacqua 2005. Speech perception in cochlear implant users: Two programming situations. Profono 17, no 1: 19-26.

Vaerenberg, B., Smits, C., De Celuaer G., Zir, E., Harman, S., Jaspers, N., Tam, Y. 2014. Cochlear implant programming: A global survey on the state of the art. The Scientific World Journal 2014: 501738.

Valente, C., H.B. Abrams, D. Benson, T.H. Chisholm, D. Citron and D. Hampton 2006. Guidelines in the audiological management of adult hearing impairment. Audiology Today 18, 32-36.

Vandali, A.E., L.A. Whitford, K.L. Plant and G.M. Clark 2000. Speech perception as a function of electrical stimulation rate: Using the nucleus 24 cochlear implant system. Ear \& Hearing 21, no 6: 608-24. 
Veekmans, K., J. Honeyman, M. Daft, K. Hawker, S. Johnson and T. Twomey 2010. The influence of increasing the instantaneous input dynamic range in paediatric cochlear implant recipients. Cochlear Implants International 11 Suppl 1: 473-8.

Verschuur C.A. 2005. Effect of stimulation rate on speech perception in adult users of the med-el cis speech processing strategy. International Journal of Audiology 44, no 1: 58-63.

Zeng, F.G., G. Grant, J. Niparko, J. Galvin, R. Shannon, J. Opie and P. Segel 2002. Speech dynamic range and its effect on cochlear implant performance. Journal of the Acoustical Society of America 111, no 1 Pt 1: 377-86.

Zhou, N. and Pfingst B.E. 2014. Effects of site-specific level adjustments on speech recognition with cochlear implants. Ear \& Hearing 35, no 1: 30-40.

Zhou, N. 2017. Deactivating stimulation sites based on low-rate thresholds improves spectral ripple and speech reception thresholds in cochlear implant users. Journal of the Acoustical Society of America 141, EL243 (2017); doi: 10.1121/1.4977235 
Table 1. Characteristics of threshold (T) level studies

\begin{tabular}{|c|c|c|c|c|c|c|c|c|}
\hline Study & $\begin{array}{l}\text { No. } \\
\text { subjects }\end{array}$ & Age & Device & Design & Assessment & $\begin{array}{l}\text { Duration of } \\
\text { experience }\end{array}$ & $\begin{array}{l}\text { OCEBM } \\
\text { Level }\end{array}$ & $\begin{array}{l}\text { Valente } \\
\text { Level }\end{array}$ \\
\hline $\begin{array}{l}\text { Baudhuin et } \\
\text { al. (2012) }\end{array}$ & 11 & $\begin{array}{l}7-17 \\
\text { years }\end{array}$ & $\begin{array}{l}\text { Advanced Bionics Hi- } \\
\text { Res90K or Cll }\end{array}$ & $\begin{array}{l}\text { Effects of two T-level settings - } 10 \text { cu below soft and } 10 \% \text { of M } \\
\text { level }\end{array}$ & $\begin{array}{l}\text { Ling } 6 \text { sounds and soundfield threshold } \\
\text { detection to FM tones. }\end{array}$ & $\begin{array}{l}2 \times 3 \text { hour } \\
\text { sessions }\end{array}$ & 3 & 3BEFII \\
\hline Boyd (2006) & 17 & $\begin{array}{l}41-70 \\
\text { years }\end{array}$ & Med-El Combi 40+ & $\begin{array}{l}\text { Three test maps were produced to examine how the } \\
\text { Programming Threshold PT setting affected acoustic thresholds } \\
\text { and speech discrimination. }\end{array}$ & $\begin{array}{l}\text { Soundfield threshold detection to FM tones for } \\
0.5,1,2 \text { and } 4 \mathrm{kHz} \text {. BKB sentences at } 65 \mathrm{dBA}- \\
\text { Test map } 2 \text { excluded. }\end{array}$ & $2-3$ minutes & 4 & 3BEFII \\
\hline $\begin{array}{l}\text { Zhou et al. } \\
\text { (2014) }\end{array}$ & $\begin{array}{l}7 \text { subjects } \\
-9 \text { ears }\end{array}$ & $\begin{array}{l}28-72 \\
\text { years }\end{array}$ & $\begin{array}{l}\text { Nucleus } 24 \\
\text { CI24RE(CA) and } \\
\text { CI24R(CS) } \\
\text { CP810 and Freedom } \\
\text { speech processor } \\
\end{array}$ & $\begin{array}{l}\text { To examine the effect of rehabilitating electrodes with poor } \\
\text { Amplitude Modulation Detection Thresholds (MDT) by increasing } \\
\text { minimum stimulation level at the poorly performing sites. }\end{array}$ & $\begin{array}{l}\text { CUNY sentences in adaptive modulated } \\
\text { background noise. SNR started at } 20 \mathrm{~dB} \text { and } \\
\text { was adapted in a one down one up procedure } \\
\text { using a } 2 \mathrm{~dB} \text { step size. SRT was taken for the } \\
\text { mean SNR of the last } 6 \text { reversals. }\end{array}$ & $\begin{array}{l}\text { Chronic, no } \\
\text { experience }\end{array}$ & 3 & 3CEFII \\
\hline $\begin{array}{l}\text { Spahr and } \\
\text { Dorman } \\
\text { (2005) }\end{array}$ & 15 & $\begin{array}{l}\text { Adult } \\
\text { subjects }\end{array}$ & Med-El Tempo+ & $\begin{array}{l}\text { Effect of three minimum stimulation level settings; behavioural T } \\
\text { level, T level at } 10 \% \text { of } \mathrm{M} \text { level or T level at } 0 \mu \mathrm{A} \text {. }\end{array}$ & $\begin{array}{l}\text { Sentences in quiet at } 54 \mathrm{~dB} \text { SPL in noise at } \\
74 \mathrm{~dB} S P L \text { with }+10 \mathrm{~dB} \text { SNR using 4-talker } \\
\text { babble. Vowels presented in the b/V/t context at } \\
54 \mathrm{~dB} \text { SPL vowel peak and Consonants in the } \\
\text { e/C/e context at } 74 \mathrm{~dB} \text { SPL vowel peak. }\end{array}$ & $\begin{array}{l}\text { Chronic, no } \\
\text { experience }\end{array}$ & 2 & 3CEFII \\
\hline $\begin{array}{l}\text { Fu et al. } \\
(2000)\end{array}$ & 3 & $\begin{array}{l}39-55 \\
\text { years }\end{array}$ & Nucleus 22 & $\begin{array}{l}\text { To determine phoneme recognition of errors in setting threshold } \\
\text { and loudness levels in cochlear implant listeners using a 4- } \\
\text { channel continuous interleaved sampling (CIS) speech } \\
\text { processor. C level remained fixed and the T level was either } \\
\text { elevated or reduced to give six dynamic range values of } 1,2,3 \text {, } \\
6,12 \text {, and } 20 \mathrm{~dB} \text {. }\end{array}$ & $\begin{array}{l}\text { Vowel recognition was measured in a 12- } \\
\text { alternative identification paradigm. Consonant } \\
\text { recognition was measured in a } 16 \text {-alternative } \\
\text { identification paradigm. All material was } \\
\text { presented at user comfort level. }\end{array}$ & $\begin{array}{l}\text { No } \\
\text { appreciable } \\
\text { experience }\end{array}$ & 4 & 4CEFII \\
\hline $\begin{array}{l}\text { Tanamati et } \\
\text { al. (2005) }\end{array}$ & 30 & $\begin{array}{l}11-66 \\
\text { years }\end{array}$ & $\begin{array}{l}\text { Med-El Combi } 40+, 16 \\
\text { subjects using } \\
\text { Tempo+ and } 14 \\
\text { subjects using CIS-Pro }\end{array}$ & $\begin{array}{l}\text { Comparison of speech perception for maps using psychophysical } \\
\text { T level setting and T at } 10 \% \text { of } C \text { level. }\end{array}$ & $\begin{array}{l}\text { Monosyllables in quiet at } 70 \mathrm{~dB} \text { SPL and } \\
\text { sentences in quiet and in noise at } 70 \mathrm{~dB} \text { SPL } \\
\text { with }+10 \mathrm{~dB} \text { SNR }\end{array}$ & 30 minutes & 3 & 3CEFII \\
\hline $\begin{array}{l}\text { Skinner et } \\
\text { al. (1999) }\end{array}$ & 8 & $\begin{array}{l}39-70 \\
\text { years }\end{array}$ & Nucleus 22 & $\begin{array}{l}\text { Comparison of two methods for setting } T \text { level; (i) Calculated } \\
\text { mean thresholds for two sessions were applied and balance for } \\
\text { loudness (ii) Threshold set between perceptually very soft and } \\
\text { medium. } A_{1} B_{1} A_{2} B_{2} \text { test design. }\end{array}$ & $\begin{array}{l}\text { Soundfield threshold detection to FM tones and } \\
\text { loudness scaling judgement for four-talker } \\
\text { babble. } \\
\text { CNC monosyllables presented at } 50,60 \text { and } \\
70 \mathrm{~dB} \text { SPL. CUNY sentences in } 8 \text { talker babble } \\
\text { presented at } 50,60 \text { and } 70 \mathrm{~dB} \text { SPL with a SNR } \\
\text { chosen for each participant to prevent ceiling } \\
\text { and floor effects. }\end{array}$ & $2-3$ weeks & 3 & 3CEV\&EFII \\
\hline
\end{tabular}


Table 2. Characteristics of IDR studies

\begin{tabular}{|c|c|c|c|c|c|c|c|c|}
\hline Study & $\begin{array}{l}\text { No. } \\
\text { subjects }\end{array}$ & Age & Device & Design & Assessment & $\begin{array}{l}\text { Duration of } \\
\text { experience }\end{array}$ & $\begin{array}{l}\text { OCEBM } \\
\text { Level }\end{array}$ & $\begin{array}{l}\text { Valente } \\
\text { Level }\end{array}$ \\
\hline $\begin{array}{l}\text { Veekmans } \\
\text { et.al. }\end{array}$ & 150 & $1.4-12.2$ years & $\begin{array}{l}\text { Nucleus 24M (86) and } \\
24 \mathrm{R}(64)\end{array}$ & $\begin{array}{l}\text { Comparison of } 30 \mathrm{~dB} \text { IIDR and } 50 \mathrm{~dB} \text { IIDR }-3 \mathrm{G} \text { to } \\
\text { Freedom }\end{array}$ & $\begin{array}{l}\text { Soundfield aided measurements at } 0.5,1,2 \text { and } \\
4 \mathrm{kHz} \text {; BKB sentences in quiet at } 60 \text { and } 50 \mathrm{BA} \\
\text { and in noise at } 60 \mathrm{dBA}+10 \text { and }+5 \mathrm{~dB} \text { SNR. }\end{array}$ & Acute & 3 & 3CEFII \\
\hline $\begin{array}{l}\text { Holden et } \\
\text { al. }\end{array}$ & 10 & $49-80$ years & $\begin{array}{l}\text { Advanced Bionics Hi- } \\
\text { Res90K or Cll }\end{array}$ & $\begin{array}{l}\text { Effect of three different IDR settings, } 50 \mathrm{~dB}, 65 \mathrm{~dB} \text { and } \\
80 \mathrm{~dB}\end{array}$ & $\begin{array}{l}\text { Soundfield threshold detection to FM tones } \\
\mathrm{CNC} \text { words at } 50 \mathrm{dBSPL} \text { and CUNY sentences } \\
\text { at } 65 \mathrm{dBSPL} \text { with four talker babble using an } \\
\text { individual subject SNR to obtain a score } \\
\text { between } 50 \text { and } 75 \% \text { correct }\end{array}$ & 1-2 weeks & 3 & 3CEFII \\
\hline $\begin{array}{l}\text { Spahr et } \\
\text { al. }\end{array}$ & 76 & $\begin{array}{l}\text { Advanced Bionics } \\
\text { Cll HiRes with } \\
\text { positioner - } 55 \\
\text { years; } \\
\text { Cochlear Cl24M or } \\
\text { RCS - } 50.5 \text { years } \\
\text { MedEL Combi } 40+\text { - } \\
52.2 \text { years }\end{array}$ & $\begin{array}{l}\text { Advanced Bionics CII } \\
\text { HiRes with positioner - } \\
26 \text { subjects; } \\
\text { Cochlear CI24M or } \\
\text { RCS - } 32 \text { subjects; } \\
\text { MedEL Combi 40+ - } \\
18 \text { subjects. }\end{array}$ & $\begin{array}{l}\text { Experiment } 3-\text { To assess the effects of increasing IDR } \\
\text { in the Cll device. }\end{array}$ & $\begin{array}{l}\text { Experiment } 3 \text { - Effect of increasing input } \\
\text { dynamic range in the CII device was assessed } \\
\text { with sentence material presented at } \\
\text { conversational levels in quiet at } 77 \mathrm{dBSPL}, \\
\text { conversational levels in noise at } 77 \mathrm{dBSPL} \\
+10 \mathrm{SNR} \text {, and soft levels in quiet at } 57 \mathrm{dBSPL}\end{array}$ & 5 minutes & 3 & 3CEFII \\
\hline $\begin{array}{l}\text { Davidson } \\
\text { et al. }\end{array}$ & 30 & $7-17$ years & $\begin{array}{l}\text { Nucleus } 24 \text { with } \\
\text { Freedom Speech } \\
\text { Processor }\end{array}$ & $\begin{array}{l}\text { Comparison of two different Instantaneous IDR (IIDR) } \\
\text { of } 30 \text { and } 40 \mathrm{~dB}\end{array}$ & $\begin{array}{l}\text { CNC wordlist at 50, and 60dBSPL, BKB } \\
\text { sentences in noise, a loudness rating task for } \\
\text { four talker speech noise, soundfield aided } \\
\text { thresholds to narrow band noise and a } \\
\text { calculated speech intelligibility index (SII). }\end{array}$ & 4 weeks & 2 & 3CEV\&EFII \\
\hline $\begin{array}{l}\text { Holden et } \\
\text { al. }\end{array}$ & 10 & $36-80$ years & $\begin{array}{l}\text { Nucleus Freedom } \\
\text { Cochlear Implant }\end{array}$ & $\begin{array}{l}\text { Comparison of two maps with different IIDR, the first } \\
\text { with an IIDR of } 30 \mathrm{~dB} \text { and the second an IIDR of } 40 \mathrm{~dB} \text {. } \\
\text { Both maps use the ACE strategy ( } 25 \mu \mathrm{s} / \mathrm{ph} \text { hase, } \\
\text { monopolar stimulation), } 1200 \text { pulses per second } \\
\text { /channel (pps/ch) stimulation rate and } 10 \text { maxima. } \\
\text { Controlled for order bias; chronic exposure. }\end{array}$ & $\begin{array}{l}\text { Soundfield threshold detection to FM tones. } \\
\text { CNC monosyllables at } 50 \mathrm{~dB} \text { SPL, HINT } \\
\text { sentences at } 50 \mathrm{~dB} \text { SPL and CUNY sentences in } \\
8 \text { talker- babble noise at } 65 \mathrm{~dB} \text { SPL with an SNR } \\
\text { chosen for each participant to prevent ceiling } \\
\text { and floor effects }\end{array}$ & 4 weeks & 3 & 3CEFII \\
\hline $\begin{array}{l}\text { Dawson et } \\
\text { al. }\end{array}$ & 9 & $50-77$ years & $\begin{array}{l}\text { Nucleus } \mathrm{Cl} 22 \text { and } \\
\text { Cl24 Cochlear } \\
\text { Implants }\end{array}$ & $\begin{array}{l}\text { Repeated measures, single subject design with chronic } \\
\text { exposure and counterbalanced order comparing IIDR of } \\
31 \mathrm{~dB} \text {, reduced T } 46 \mathrm{~dB}, 46 \mathrm{~dB} \text {, reduced T } 56 \mathrm{~dB} \text { and } 56 \\
\mathrm{~dB} \text {. }\end{array}$ & $\begin{array}{l}\text { CNC monosyllables presented at } 45 \text { and } 55 \mathrm{~dB} \\
\text { SPL (RMS). CUNY sentences resented at } 65 \mathrm{~dB} \\
\text { SPL in } 8 \text { talker-babble noise with an SNR } \\
\text { chosen for each participant to prevent ceiling } \\
\text { and floor effects }\end{array}$ & 4 weeks & 3 & 3CEV\&EFII \\
\hline $\begin{array}{l}\text { James et } \\
\text { al. }\end{array}$ & 12 & $59-83$ years & Nucleus 24 & $\begin{array}{l}\text { Part } 2 \text { - of the experimental design varied instantaneous } \\
\text { input dynamic (IIDR) }\end{array}$ & $\begin{array}{l}\text { Soundfield threshold detection to FM tones } \\
\text { Consonants in the a/C/a context; vowels in the } \\
\text { h/V/d context at } 40 \text { and } 55 \mathrm{~dB} \text { SPL. BKB } \\
\text { sentences at } 65 \mathrm{~dB} \text { SPL with } 8 \text { talker babble with } \\
\text { an SNR chosen for each participant to prevent } \\
\text { ceiling and floor effects }\end{array}$ & $2-3$ weeks & 3 & 3CEV\&EFII \\
\hline
\end{tabular}


Table 3. Characteristics of stimulation rate studies

\begin{tabular}{|c|c|c|c|c|c|c|c|c|}
\hline Study & No. subjects & Age & Device & Design & Assessment & $\begin{array}{l}\text { Duration of } \\
\text { experience }\end{array}$ & $\begin{array}{l}\text { OCEBM } \\
\text { Level }\end{array}$ & $\begin{array}{l}\text { Valente } \\
\text { Level }\end{array}$ \\
\hline $\begin{array}{l}\text { Arora et } \\
\text { al. }\end{array}$ & $\begin{array}{l}10 \text { with inclusion of } \\
\text { speech test results from } \\
8 \text { subjects from an } \\
\text { earlier study in } 2009\end{array}$ & $\begin{array}{l}58- \\
74 \\
\text { years }\end{array}$ & Cochlear Nucleus Cl24 & $\begin{array}{l}\text { Effect of low to moderate stimulation rates }(275,350, \\
500 \text { and } 900 \mathrm{pps} / \mathrm{ch}) \text { on modulation detection } \\
\text { threshold (MDT) ability. The relationship between } \\
\text { MDT and speech perception as a function of rate was } \\
\text { examined. }\end{array}$ & $\begin{array}{l}\text { Four lists CNC monosyllabic words in quiet at } \\
60 \mathrm{~dB} \text { SPL RMS and an adaptive SRT using } \\
\text { speech intelligibility test (SIT) sentences at } 65 \mathrm{~dB} \\
\text { SPL using four talker babble proving an SNR }\end{array}$ & 24 hours & 3 & 3CEV\&EFII \\
\hline $\begin{array}{l}\text { Balkany et } \\
\text { al. }\end{array}$ & 71 & $\begin{array}{l}23- \\
90 \\
\text { years }\end{array}$ & $\begin{array}{l}\text { Cochlear Nucleus } \\
\text { Freedom }\end{array}$ & $\begin{array}{l}\text { Multi-centre randomised, controlled, prospective, } \\
\text { single-blinded, single subject repeat measures } \\
\text { design. }\end{array}$ & $\begin{array}{l}\text { Soundfield threshold detection } 0.25 \text { to } 8 \mathrm{kHz} \text { for } \\
\text { FM tones } \\
\text { HINT sentences in quiet at } 60 \mathrm{~dB} \text { SPL, CNC } \\
\text { words/ phonemes in quiet at } 60 \text { and } 70 \mathrm{~dB} \text { SPL. } \\
\text { HINT sentences in noise at } 60 \mathrm{~dB} \text { SPL SNR } \\
10 \mathrm{~dB} \text { and CUNY sentences in noise at } 70 \mathrm{~dB} \\
\text { SPL SNR 10dB }\end{array}$ & 2-4 weeks & 2 & 3CEV\&EFII \\
\hline $\begin{array}{l}\text { Battmer et } \\
\text { al. }\end{array}$ & $\begin{array}{l}\text { Group } 1-29 \text { subjects } \\
\text { Group } 2-19 \text { subjects } \\
\text { Group } 3-20 \text { subjects }\end{array}$ & $\begin{array}{l}24- \\
72 \\
\text { years } \\
19- \\
77 \\
\text { years } \\
24- \\
80 \\
\text { years }\end{array}$ & $\begin{array}{l}\text { Cochlear Nucleus } \\
\text { Cl24RE }\end{array}$ & $\begin{array}{l}\text { Group } 1 \text { - Comparison of the effects of different } \\
\text { pulse rates on speech perception performance } \\
\text { (subjects had prior experience with 1200pps) } \\
\text { Group } 2 \text { - Preferred pulse rate post activation (no } \\
\text { within-subject comparison for the effect of pulse rate) } \\
\text { Group } 3 \text { - Randomised, single blinded, subjects } \\
\text { offered two pulse rates at activation }\end{array}$ & $\begin{array}{l}\text { Freiburg words at } 60 \text { and } 70 \mathrm{~dB} \text { SPL, Oldenburg } \\
\text { sentences in quiet at } 65 \mathrm{~dB} \text { SPL and in noise at } \\
65 \mathrm{~dB} \text { SPL scored as an SNR at } 50 \% \text { correct or } \\
\text { SNR } \\
\text { Disyllabic word test in quiet and at a fixed SNR }\end{array}$ & 5-33 weeks & 3 & 3CEV\&EFII \\
\hline $\begin{array}{l}\text { Bonnet et } \\
\text { al. }\end{array}$ & 27 & $\begin{array}{l}17- \\
77 \\
\text { years }\end{array}$ & $\begin{array}{l}\text { Advanced Bionics Cll } \\
\text { and Hi-Res90K }\end{array}$ & $\begin{array}{l}\text { To assess } 9 \text { different } 12 \text { channel strategies using } \\
\text { monopolar mode, biphasic pulses and no interphase } \\
\text { gap. An interpulse interval was used to maintain rate } \\
\text { where pulse width was manipulated. }\end{array}$ & $\begin{array}{l}\text { Dutch monosyllabic consonant-vowel-consonant } \\
\text { word test in quiet at } 65 \mathrm{~dB} \text { SPL and in noise at } \\
+10 \text { and }+5 \mathrm{~dB} \text { SNR using speech shaped noise. }\end{array}$ & 1 hour & 3 & 3CEFII \\
\hline $\begin{array}{l}\text { Buechner } \\
\text { et al. }\end{array}$ & 13 & $\begin{array}{l}17.7- \\
73.0 \\
\text { years }\end{array}$ & $\begin{array}{l}\text { Advanced Bionics Cll } \\
\text { with Hi-Focus electrode } \\
\text { array and electrode } \\
\text { positioned system }\end{array}$ & $\begin{array}{l}\text { A prospective repeated-measure in a chronic } \\
\text { balanced cross-over design evaluating the influence } \\
\text { upon speech perception of different stimulation rates } \\
\text { and the use of sequential or paired stimulation } \\
\text { patterns. }\end{array}$ & $\begin{array}{l}\text { Freiburger monosyllable word test in quiet, HSM } \\
\text { sentence test in quiet and in noise with } 10 \mathrm{~dB} \\
\text { SNR }\end{array}$ & 4 weeks & 3 & 3CEV\&EFII \\
\hline $\begin{array}{l}\text { Di Lella et } \\
\text { al. }\end{array}$ & 10 & $\begin{array}{l}28- \\
66 \\
\text { years }\end{array}$ & Neurelec-MXM & $\begin{array}{l}\text { Prospective within subject repeated measures design } \\
\text { to evaluate the speech recognition performance } \\
\text { using the MPIS strategy at two stimulation rates }\end{array}$ & $\begin{array}{l}\text { NU } 6 \text { word list and CID sentences presented live } \\
\text { at } 70 \mathrm{~dB} \text { SPL voice in quiet and in talker babble } \\
\text { noise at }+10 \mathrm{~dB} \text { SNR }\end{array}$ & 6 weeks & 3 & 3CEV\&EFII \\
\hline $\begin{array}{l}\text { Friesen et } \\
\text { al. }\end{array}$ & $\begin{array}{l}\text { Advanced Bionics } \mathrm{Cl} \text {, } \\
\mathrm{N}=5 \text {; Cochlear Nucleus } \\
24, \mathrm{~N}=4 \text {; Advanced } \\
\text { Bionics } \mathrm{Cll}, \mathrm{N}=3\end{array}$ & $\begin{array}{l}38- \\
66 \\
\text { years }\end{array}$ & $\begin{array}{l}\text { Advanced Bionics } \mathrm{Cl}, \\
\text { Cochlear Nucleus } 24 \\
\text { and Advanced Bionics } \\
\text { Cll }\end{array}$ & $\begin{array}{l}\text { To investigate speech perception following } \\
\text { adjustment of rate and stimulus channel number. }\end{array}$ & $\begin{array}{l}\text { Vowels in } \mathrm{h} / \mathrm{V} / \mathrm{d} \text { context } \\
\text { Consonants in a/C/a context. } \\
\mathrm{CNC} \text { wordlist, HINT sentences and IEEE } \\
\text { sentences. Materials presented at } 65 \mathrm{~dB} \text { SPL for } \\
\mathrm{Cl} \text { and N24; 70dB SPL for Cll. }\end{array}$ & $\begin{array}{l}\text { Chronic, no } \\
\text { experience }\end{array}$ & 3 & 3CEFII \\
\hline $\begin{array}{l}\text { Holden et } \\
\text { al. }\end{array}$ & 8 & $\begin{array}{l}36- \\
81 \\
\text { years }\end{array}$ & $\begin{array}{l}\text { Cochlear Nucleus } \\
\text { Cl24M }\end{array}$ & $\begin{array}{l}\text { To evaluate speech recognition with the ACE } \\
\text { strategy at two stimulation rates } 720 \mathrm{pps} / \mathrm{ch} \text { and } \\
\text { 1800pps/ch and to determine if the group or } \\
\text { individuals performed better or demonstrated a } \\
\text { preference following chronic exposure }\end{array}$ & $\begin{array}{l}\text { Soundfield threshold detection } 0.25 \text { to } 6 \mathrm{kHz} \text { for } \\
\text { FM tones } \\
\text { CNC monosyllables and CUNY sentences } \\
\text { presented in at } 50,60 \text { and } 70 \mathrm{~dB} \text { SPL with } 8 \\
\text { talker babble noise. } \\
\text { Preference questionnaire. }\end{array}$ & 3-4 weeks & 3 & 3CEV\&EFII \\
\hline
\end{tabular}


Table 3. (continued)

\begin{tabular}{|c|c|c|c|c|c|c|c|c|}
\hline Kiefer et al. & 13 & $\begin{array}{l}\text { Not } \\
\text { descri } \\
\text { bed }\end{array}$ & $\begin{array}{l}\text { Med-El Combi } 40 \mathrm{~N}=9 \\
\text { Med-El Combi } 40+\mathrm{N}=4\end{array}$ & $\begin{array}{l}\text { To systematically evaluate the reduction of } \\
\text { stimulation rate from } 1515 \text { and } 1730 \text { ppse to } \\
600 \text { ppse and channel number from } 8 \text { to } 4 .\end{array}$ & $\begin{array}{l}\text { Eight German vowels in } \mathrm{b} / \mathrm{V} / \mathrm{b} \text { context and } \\
\text { sixteen consonants in } \mathrm{a} / \mathrm{C} / \mathrm{a} \text { context at } \\
65 \mathrm{dBHL} . \\
\text { Freiburg monosyllabic words and 2-digit }\end{array}$ & 10 minutes & 3 & 3CEFII \\
\hline $\begin{array}{l}\text { Loizou et } \\
\text { al. }\end{array}$ & 6 & $\begin{array}{l}40-68 \\
\text { years }\end{array}$ & $\begin{array}{l}\text { Med-EI Link } \\
\text { experimental device }\end{array}$ & $\begin{array}{l}\text { To systematically evaluate the effect of stimulation } \\
\text { rate on speech perception. }\end{array}$ & $\begin{array}{l}\text { CNC monosyllabic words, } 20 \text { consonants in } v / C / v \\
\text { context and vowels in } \mathrm{h} / \mathrm{V} / \mathrm{d} \text { context. Presented at } \\
\text { a 'comfortable' listening level. }\end{array}$ & $\begin{array}{l}\text { Chronic, no } \\
\text { experience }\end{array}$ & 3 & 3CEFII \\
\hline Nie et al. & 5 & $\begin{array}{l}24-57 \\
\text { years }\end{array}$ & Med-El Combi 40+ & $\begin{array}{l}\text { Experiment 2. To evaluate the variation of stimulation } \\
\text { rate from } 1000 \text { to } 4000 \mathrm{~Hz} \text { per electrode on four fixed } \\
\text { pairs of electrodes }\end{array}$ & $\begin{array}{l}12 \text { vowels in } \mathrm{h} / \mathrm{V} / \mathrm{d} \text { context and } 20 \text { consonants in } \\
\text { a/C/a context. } \\
\text { HINT sentences male speaker in quiet and in } \\
\text { noise at } 10 \mathrm{~dB} \text { SNR, presented at user } \\
\text { comfortable listening level. }\end{array}$ & 10 minutes & 3 & 3CEFII \\
\hline Park et al. & 6 & $\begin{array}{l}17-43 \\
\text { years }\end{array}$ & Nucleus 24 contour & $\begin{array}{l}\text { To investigate speech recognition performance of } \mathrm{Cl} \\
\text { users in quiet and in noise for moderate and high } \\
\text { stimulation rates - 900ppse and 2400ppse. } \\
\text { Prospective, cross-over study design, chronic } \\
\text { exposure. }\end{array}$ & $\begin{array}{l}\text { Monosyllabic wordlist, presented at } 45 \mathrm{dBHL} . \\
\text { Sentence test in white noise presented at } \\
50 \mathrm{dBHL} \text { with } 15 \mathrm{~dB} \text { SNR initially adapted to } \\
\text { maintain a target correct of } 70 \% \text {. } \\
\text { Preference questionnaire. }\end{array}$ & 2 weeks & 3 & 3CEV\&EFII \\
\hline Plant et al. & 15 & $\begin{array}{l}26.9- \\
75.2 \\
\text { years }\end{array}$ & $\begin{array}{l}\text { Cochlear Nucleus } \\
\text { Cl24RE with contour } \\
\text { electrode }\end{array}$ & $\begin{array}{l}\text { A repeat measures single subject design using an } \\
\text { ABAB protocol. Program } A \text { used a stimulation rate } \\
\text { between } 12 \mathrm{kHz} \text { and } 14.4 \mathrm{kHz} \text { and program B used a } \\
\text { stimulation rate of either } 24 \mathrm{kHz} \text { or } 32 \mathrm{kHz} \text { dependent } \\
\text { upon subject preference. }\end{array}$ & $\begin{array}{l}\text { CNC monosyllables in quiet at } 60 \mathrm{~dB} \text { SPL RMS } \\
\text { and CUNY sentences in quiet at } 65 \mathrm{~dB} \text { SPL RMS } \\
\text { and in noise using } 8 \text { talker babble with an SNR } \\
\text { between }+5 \mathrm{~dB} \text { and }+14 \mathrm{~dB} \text { adjusted for } \\
\text { individuals to prevent floor and ceiling effects. }\end{array}$ & 2-24 weeks & 3 & 3CEV\&EFII \\
\hline Plant et al. & 12 & $\begin{array}{l}32-76 \\
\text { years }\end{array}$ & $\begin{array}{l}\text { Cochlear Nucleus } \\
\text { Cl24M }\end{array}$ & $\begin{array}{l}\text { Assess the effect of parameter adjustments in the } \\
\text { ACE and CIS strategies. Study II. Evaluation of CIS } \\
\text { stimulation rates of } 275,900,1800 \text { and } 2400 \mathrm{~Hz} \text { for a } \\
\text { fixed six channel program. } \\
\text { Balanced order across sessions and subjects to limit } \\
\text { order and learning effects. }\end{array}$ & $\begin{array}{l}\text { CNC monosyllables in quiet at } 65 \mathrm{dBA} \text { and CUNY } \\
\text { sentences presented at } 65 \mathrm{dBA} \text { in eight-talker } \\
\text { babble noise at a SNR specific to each test } \\
\text { subject to limit floor and ceiling effects }\end{array}$ & $\begin{array}{l}\text { Chronic, no } \\
\text { experience }\end{array}$ & 3 & 3CEFII \\
\hline $\begin{array}{l}\text { Shannon et } \\
\text { al. }\end{array}$ & 7 & $\begin{array}{l}33-59 \\
\text { years }\end{array}$ & $\begin{array}{l}\text { Advanced Bionics Cll } \\
\text { with Hi-Focus electrode } \\
\text { array and electrode } \\
\text { positioned system }\end{array}$ & $\begin{array}{l}\text { Evaluate the effect of stimulation rate and channel } \\
\text { number on speech perception. Pulse rate varied } \\
\text { between } 600 \text { and 4800ppse in an acute experimental } \\
\text { design. }\end{array}$ & $\begin{array}{l}\text { Medial Vowel in the } \mathrm{h} / \mathrm{V} / \mathrm{d} \text { context and Medial } \\
\text { Consonant recognition in the a/C/a context, CNC } \\
\text { words and IEEE sentences presented in quiet at } \\
70 \mathrm{dBA} \text { and in speech shaped noise at }+10 \mathrm{~dB} \\
\text { SNR }\end{array}$ & Acute & 4 & 3CEFII \\
\hline $\begin{array}{l}\text { Vandali et } \\
\text { al. }\end{array}$ & $\begin{array}{l}6 \text { recruited, } 5 \text { data sets } \\
\text { reported }\end{array}$ & $\begin{array}{l}44-70 \\
\text { years }\end{array}$ & $\begin{array}{l}\text { Cochlear Nucleus } \\
\text { CI24M, SPEAK speech } \\
\text { processing strategy and } \\
\text { SPRINT speech }\end{array}$ & $\begin{array}{l}\text { To investigate the effect of varying electrical } \\
\text { stimulation rate on speech comprehension. } \\
\text { A repeated } A B C \text { design with alternating order with } \\
\text { chronic exposure to each stimulation rate. }\end{array}$ & $\begin{array}{l}\text { CNC monosyllables in quiet and CUNY } \\
\text { sentences in multi-talker noise at three SNRs } \\
\text { which were subject dependent to limit floor and } \\
\text { ceiling effects }\end{array}$ & 4 weeks & 3 & 3CEFII \\
\hline Verschuur & 6 & $\begin{array}{l}29-73 \\
\text { years }\end{array}$ & $\begin{array}{l}\text { Med-El Combi } 40+\text { and } \\
\text { Ineraid Cochlear Implant } \\
\text { systems }\end{array}$ & $\begin{array}{l}\text { Determine the effect of altering channel stimulation } \\
\text { rate. Three stimulation rates assessed, the subjects } \\
\text { clinical rate, 400pps/ch and } 800 \mathrm{pps} / \mathrm{ch} \text {. Order of rate } \\
\text { condition and test within each rate condition was } \\
\text { counterbalanced in an experimental acute design }\end{array}$ & $\begin{array}{l}\text { Categorical perception of synthetic speech stimuli } \\
\text { with varied acoustic cues; consonant recognition } \\
\text { measure (VCV) in the i/C/i context and BKB } \\
\text { sentences administered in quiet at } 70 \mathrm{dBA}\end{array}$ & 30 minutes & 3 & 3CEFII \\
\hline
\end{tabular}


Table 4. Summary

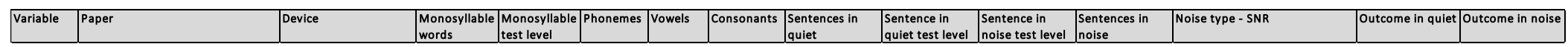

\begin{tabular}{|c|c|c|c|c|c|c|c|c|c|c|c|c|c|c|}
\hline \multirow{7}{*}{ T Level } & \multicolumn{14}{|c|}{ Effect of $T$ level increase or decreasing electrical dynamic range } \\
\hline & 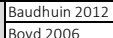 & AABionics CII HiRes90\% & & & & & & $B \times B$ & $65 \mathrm{SBA}$ & & & & & \\
\hline & Fu2000 & 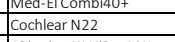 & - & & & + & + & BKB & $600 \mathrm{BA} A$ & & & & $=$ & \\
\hline & Skinner 1999 & $\begin{array}{l}\text { ABioinisc CCH HiRes90K } \\
\text { Cochlear N22 }\end{array}$ & ++ & 50,60 and & ++ & & & cuny & 50,60 and & & & & t++ & \\
\hline & Spahr 2005 & Med-El Tempo+ & & & & $=$ & $=$ & $\begin{array}{l}\text { CONEERAATINANAL } \\
\text { SENTENESTYYE }\end{array}$ & 54dBSPL & 74dBSPL & $\begin{array}{l}\text { CONVERSATONAL } \\
\text { SENTENESTSLE }\end{array}$ & $\begin{array}{l}74 \text { d dSPLLat }+10 \text { dBSNR, 4-talker } \\
\text { babble }\end{array}$ & $=$ & $=$ \\
\hline & Tanamati 2005 & Med-El Combi40+ & $=$ & 70dBSPL & & & & $\begin{array}{l}\text { PORTUGUESE } \\
\text { SENTENCES }\end{array}$ & 70dBSPL & 70dBSPL & \begin{tabular}{|l|} 
PORTUGUESE \\
SENTENCES \\
\end{tabular} & $\begin{array}{l}70 \text { 7od SPL Lat +10dB SNR, noise type } \\
\text { not specfied }\end{array}$ & $=$ & $=$ \\
\hline & zhou 2014 & $\begin{array}{l}\text { Cochlear N24, CP810 anc } \\
\text { Freedom SP }\end{array}$ & & & & & & & & 60dBA & CUNY & $\begin{array}{l}\text { Adapative modulated white noise } \\
\text { with SNR at SRT - 50\% correct }\end{array}$ & & + \\
\hline
\end{tabular}

\begin{tabular}{|c|c|c|c|c|c|c|c|c|c|c|c|c|c|c|}
\hline \multirow{8}{*}{ IDR } & 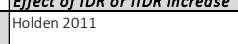 & ABionics CII HiRes90K & ++ & 50dBSPL & & & & & & 65dBSPL & CUNY & SNR limiting floor and celling +5 to & & $=$ \\
\hline & Veekmans 2010 & Cochlear N24 & & & & & & ВКв & $50,60 \mathrm{dBA}$ & 60dBA & ВКВ & $\begin{array}{l}\text { Noise type not specified, SNR }+10 \mathrm{~dB} \\
\text { and } 5 \mathrm{~dB}\end{array}$ & - & + \\
\hline & Davidson 2009 & Cochlear N24, Freedom SP & +t+ & 50, 60dBSPL & & & & & & 65dBSPL & BKB-SIN & $\begin{array}{l}\text { Four talker babble with SNR at SRT- } \\
50 \% \text { correct calculated }\end{array}$ & & $=$ \\
\hline & Holden 2007 & Cochlear N24 & +++ & 50dBSPL & t++ & $=$ & +++ & HINT & 50dBSPL & 65dBSPL & CUNY & Eight talker babble, SNR limiting floor & $=$ & + \\
\hline & Spahr 2007 & $\begin{array}{l}\text { ABionics CIII Hires9ok, } \\
\text { Cochlear r24, MedEl, } \\
\text { Combi } 40+\end{array}$ & & & & & & cuny & $57,77 \mathrm{dBSPL}$ & 77dBSPL & $A Z-B I O$ & Four talker babble - + 10 dB SNR & + & + \\
\hline & Dawson & Cochlear N22 and N24 & +++ & $45,55 \mathrm{dBSPL}$ & & +++ & t+t & & & 65dBSPL & CUNY & $\begin{array}{l}\text { Eight takker babble, SNR to limiting } \\
\text { floor and celing }\end{array}$ & & $=$ \\
\hline & James 2003 & Cochlear N24 & & & & $=$ & t+ & & & 65dBSPL & BКB & $\begin{array}{l}\text { Eight talker babble, SNR to limiting } \\
\text { floorand cering }\end{array}$ & &.- \\
\hline & Zeng 2002 & ABionics C1 & & & & +t+ & t+ & & & & & $\begin{array}{l}\text { Speech spectrum shaped noise, SNR } \\
+5 \text { Sd }\end{array}$ & & \\
\hline
\end{tabular}

\begin{tabular}{|c|c|c|c|c|c|c|c|c|c|c|c|c|c|c|}
\hline \multirow{16}{*}{ Rate } & \begin{tabular}{|l} 
Effect of stimulation rate increase \\
Arora 2011
\end{tabular} & Cochlear N24 & $=$ & Sdpse & & & & & & 65. & ST & Four talker babble with SNR at SRT- & & 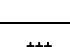 \\
\hline & \begin{tabular}{|l|} 
Balkany 2007 \\
\end{tabular} & Cochlear N24 & $=$ & $60,70 \mathrm{dSSPL}$ & & & & HINT-O & $60 \mathrm{dBSPL}$ & $60.70 \mathrm{dBSPL}$ & HINT CUNY & \begin{tabular}{|l}
$50 \%$ correct calculated \\
Noise type not specified, SNR +10dB
\end{tabular} & - & $++t$ \\
\hline & Battmer 2010 & Cochlear N24 & $=$ & $60,70 \mathrm{dBSPL}$ & & & & & 65dBSPL & 65dBSPL & OLDENBURG & \begin{tabular}{|l} 
Noise type not specified, SNR at SRT \\
s.o\% crecectcalculat,
\end{tabular} & & - \\
\hline & Bonnet 2012 & ABionics CII HiRes90K & $=$ & 65dBSPL & & & & & & & & $\begin{array}{l}\text { Speech Shaped noise, } S N R+5 d B \text { and } \\
+10 \mathrm{~d} B\end{array}$ & & \\
\hline & Buechner 2010 & ABionics CII & +t & Not specified & & & & HSM & & & HSM & 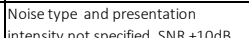 & + & + \\
\hline & Di Lella 2010 & Neurelec MXM & ++ & 70dBSPL & & & & $\mathrm{CID}$ & & 70dBSPL & $\mathrm{CID}$ & Talker babble, +10dB SNR & ++ & ++ \\
\hline & Friesen 2005 & ABionics $\mathrm{C1}$ 1, Cochlear N24, & $=$ & $65,70 \mathrm{dBSPL}$ & & $=$ & $=$ & HINT/IEEE & & $65,70 \mathrm{dBSPL}$ & & & $=$ & \\
\hline & Holden 2002 & Cochlear N24 & & & + & & & CUNY & & $\begin{array}{l}50,60 \text { and } \\
70 \mathrm{dSSP}\end{array}$ & CUNY & $\begin{array}{l}\text { Eight talker babble, SNR Rimiting floor } \\
\text { ald celilg }\end{array}$ & & +++ \\
\hline & Kiefer 2000 & Med-El Combi40+ & ++ & 75dвHL & & & + & & & & & & & \\
\hline & Loizou 2000 & Med-El Link device & + & Comfortable & & $=$ & t+t & & & & & & & \\
\hline & Nie 2006 & Med-El Combi40+ & & Comfortable & & $=$ & + & HINT & & Comfortable & HINT & Single female talker at 10dB SNR & & \\
\hline & Park 2007 & Cochlear N24 & - & 45 dB̈HL & & & & & & 50dBHL & $\begin{array}{l}\text { KOREAN } \\
\text { STANDARD } \\
\text { SENTENCES }\end{array}$ & White noise, adaptive SNR & & $=$ \\
\hline & Plant 2007 & Cochlear N24 & $=$ & 60dBSPL & & & & & & 65dBSPL & CUNY & $\begin{array}{l}\text { Multitiaker babble, SNR limiting } \\
\text { flocand andiling }\end{array}$ & & $=$ \\
\hline & Plant 2002 & Cochlear N24 & $=$ & $65 \mathrm{dBA}$ & & & & & & $65 \mathrm{dBA}$ & CUNY & Eight talker babble, SNR limiting floor & & $=$ \\
\hline & Shannon 2011 & ABionics CII & $=$ & $70 \mathrm{dBA}$ & & ++ & $=$ & IEEE & $70 \mathrm{dBA}$ & 70dBA & IEEE & $\begin{array}{l}\text { Speech spectrum shaped noise, SNR } \\
+10 \mathrm{dadB}\end{array}$ & $=$ & $=$ \\
\hline & Vandali 2000 & Cochlear N24 & $=$ & 70dBSPL & & -. & $=$ & & & 70dBSPL & CUNY & $\begin{array}{l}\text { Multit-alker babble, three SNRs - } \\
\text { low middleand hig }\end{array}$ & & $\ldots / \ldots$ \\
\hline
\end{tabular}

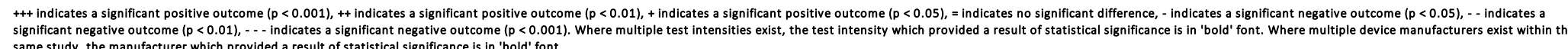

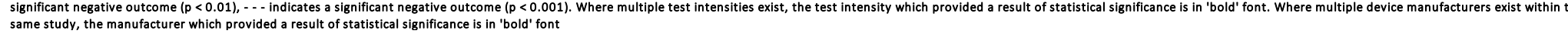


FIG. 1. MEDLINE/ EMBASE search strategy

"Cochlear Implants"

"Cochlear Implantation"

"Cochlea\$ Implant\$"

"Cochlea\$ adj2 implant\$"

"Cochlea\$ adj2 prosthes\$"

"Cochlea\$ adj2 prosthet\$"

"Speech adj2 percept"

"Speech adj2 understand"

"Speech recognition"

"Threshold level\$"

"T level"

"Stimulat\$ adj2 level\$"

"Stimulat\$ adj2 threshold\$"

"Input dynamic range"

"IDR"

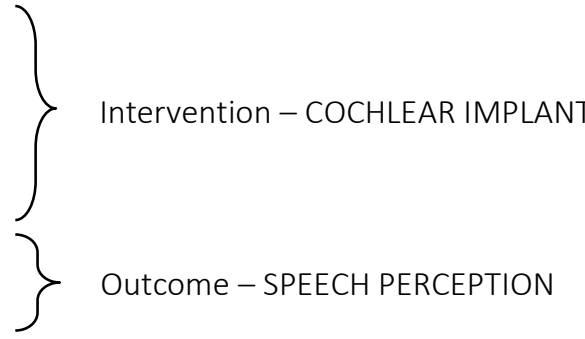

"Stimulation rate"

"PPS\$ stimulat\$

"Pulse rate"

"Carrier pulse rate"

"Pulsatile stimulation"

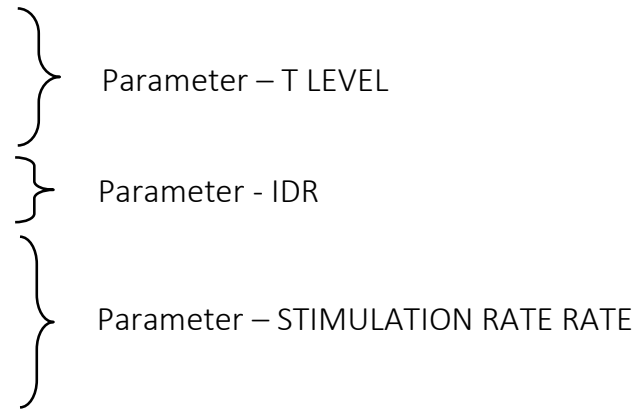

Key

$\$=$ retrieve unlimited suffix variations

$\operatorname{adj} 2$ = searches for terms that are (2) spaces away from each other 
FIG. 2. Flow chart of selection method

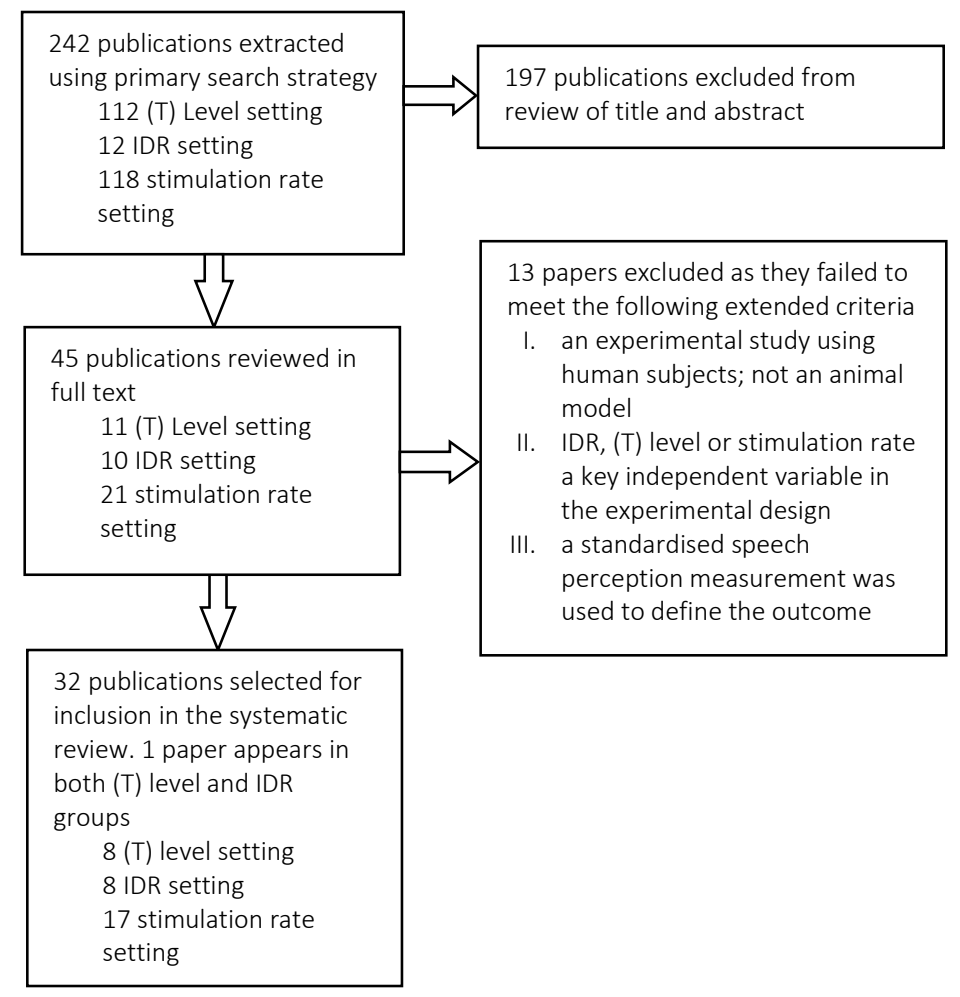


FIG. 3. Quality of studies

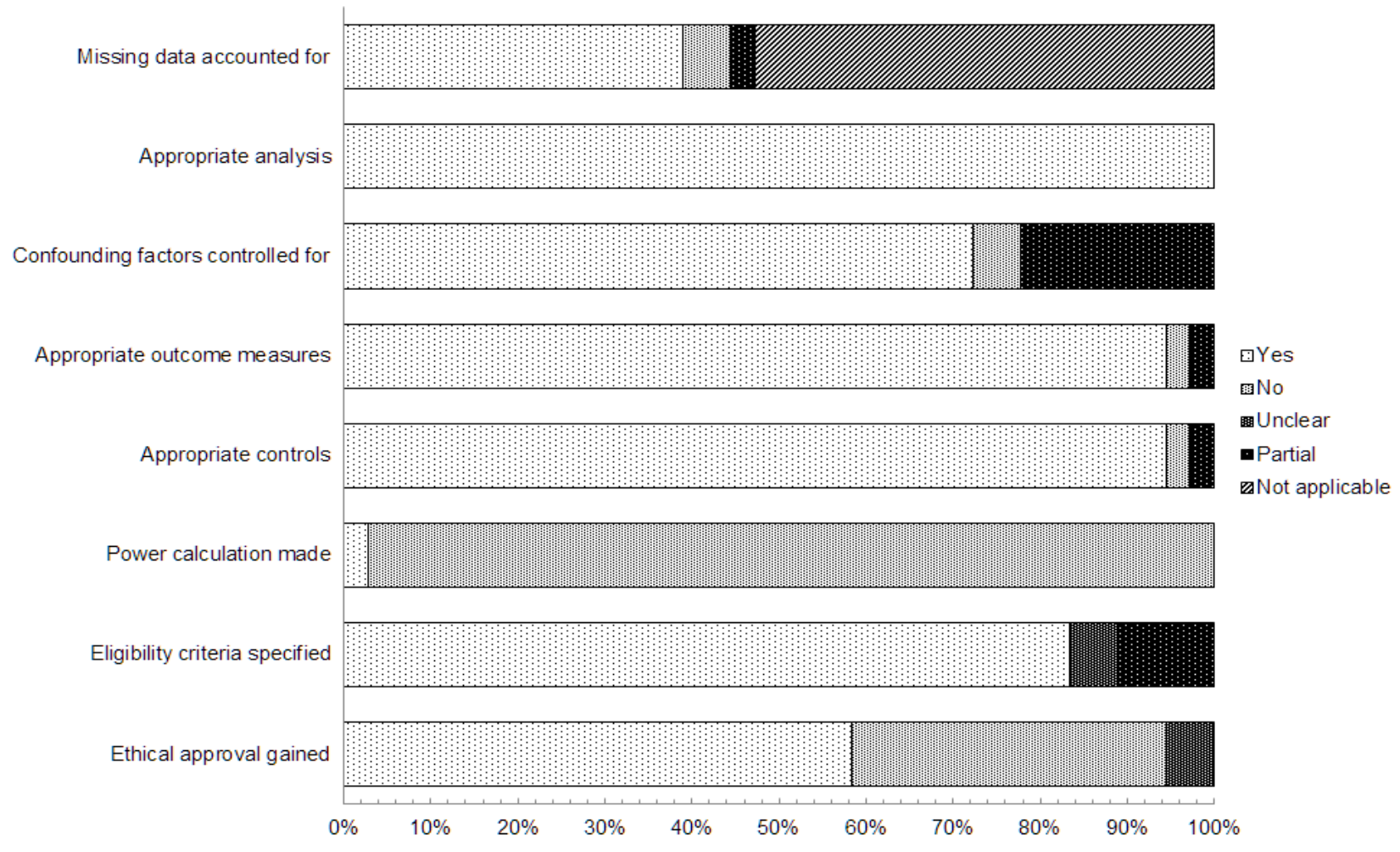


FIG. 4.

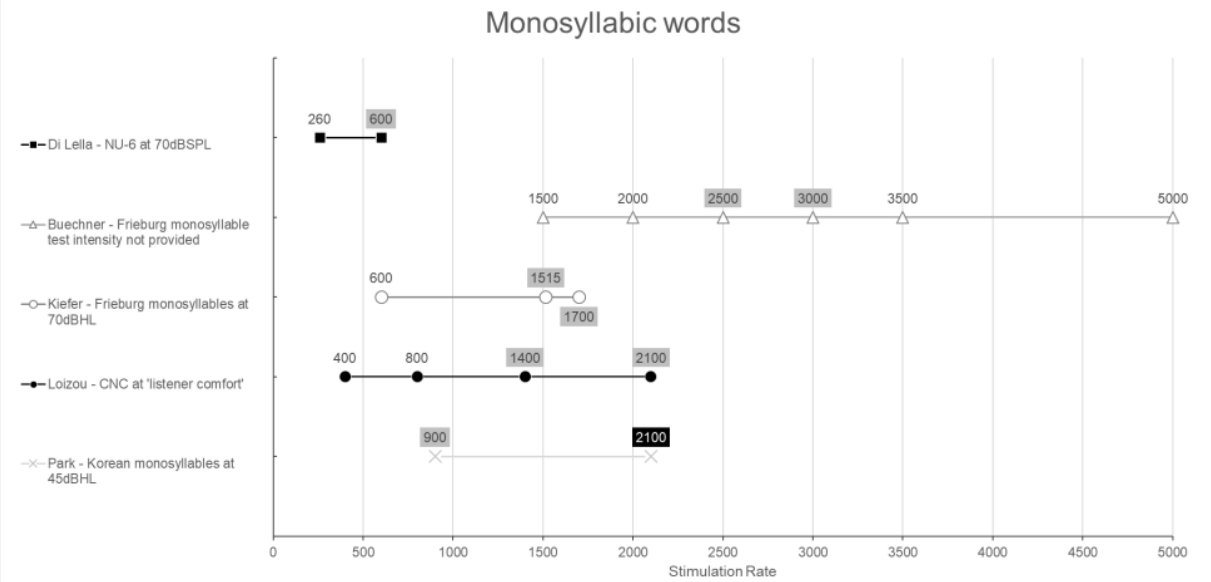

Stimulation rates within each study providing a significant improvement in speech perception score are in grey; rates providing a significant decrease in speech perception score, which coincide with a higher stimulation rate are in black. 
FIG.5.

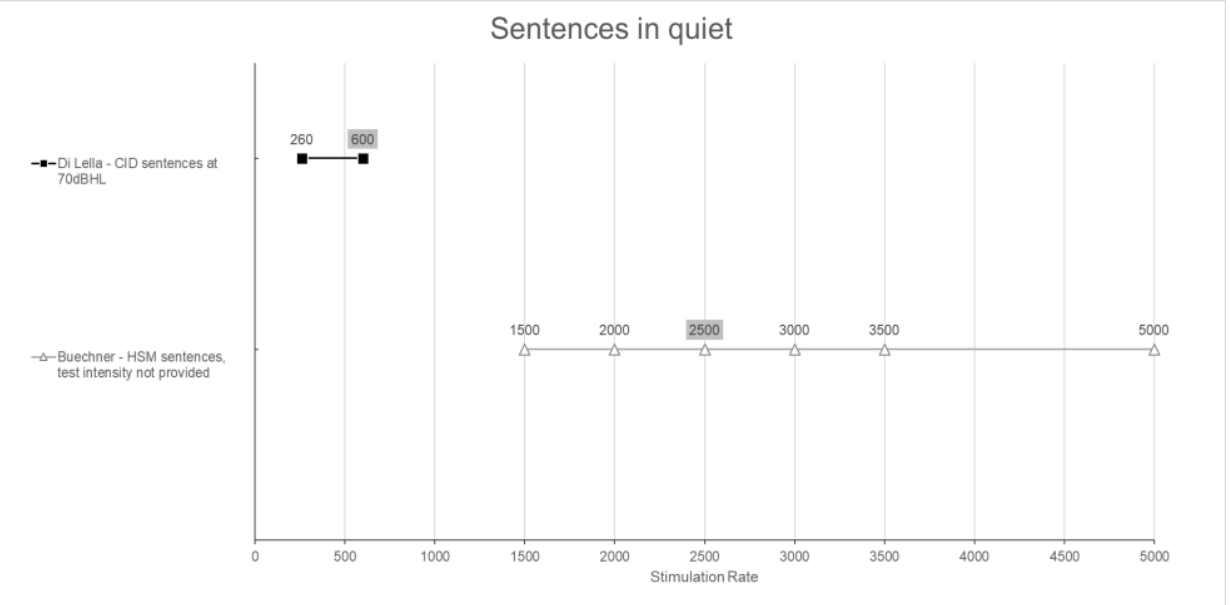

Plot of stimulation rate change evaluated by studies using sentence perception in quiet as an outcome. Rates providing a significant improvement in perception in quiet are in grey. 
FIG.6.

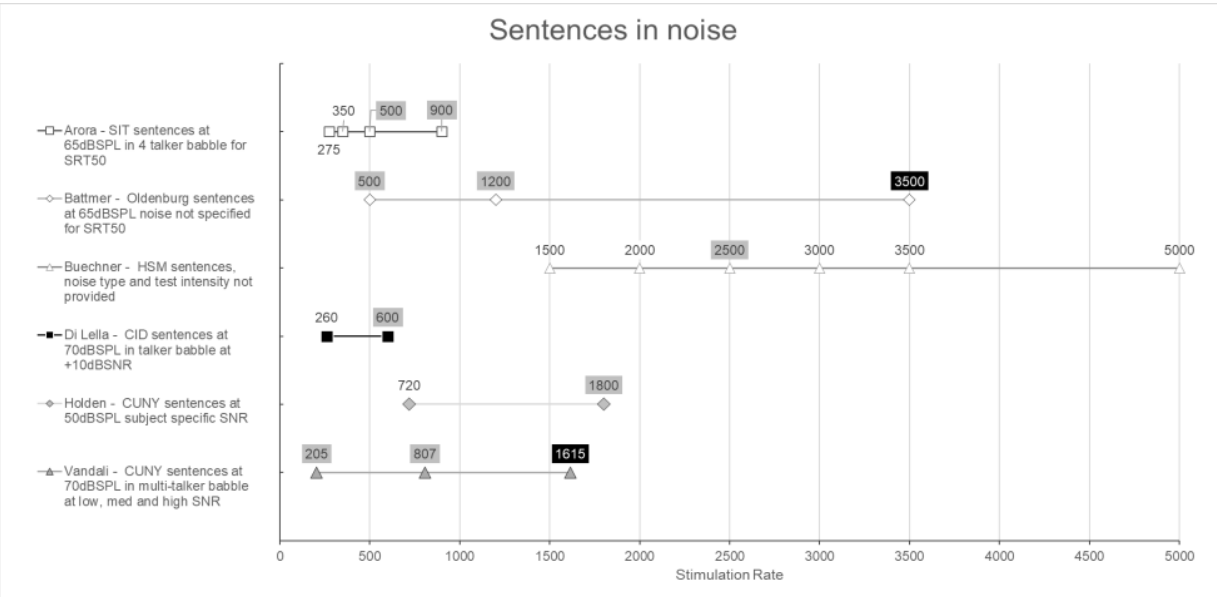

Plot of stimulation rate change evaluated by studies using sentence in noise perception as an outcome. Rates providing a significantly improved perception score are in grey; rates providing a significant decrease, which coincide with a higher stimulation rate are in black. 